\title{
Stress-Breakdown Time and Slip- Weakening Distance Inferred from Slip-Velocity Functions on Earthquake Faults
}

\section{$\operatorname{AUTHOR}(\mathrm{S})$ :}

Mikumo, Takeshi; Olsen, Kim B.; Fukuyama, Eiichi; Yagi, Yuji

\section{CITATION:}

Mikumo, Takeshi ...[et al]. Stress-Breakdown Time and Slip-Weakening Distance Inferred from Slip-Velocity Functions on Earthquake Faults. Bulletin of the Seismological Society of America 2003, 93(1): 264-282

ISSUE DATE:

2003-02

URL:

http://hdl.handle.net/2433/193410

RIGHT:

(C) 2003 by the Seismological Society of America 


\title{
Stress-Breakdown Time and Slip-Weakening Distance Inferred from Slip-Velocity Functions on Earthquake Faults
}

\author{
by Takeshi Mikumo, Kim B. Olsen, Eiichi Fukuyama, and Yuji Yagi*
}

\begin{abstract}
We estimate the critical slip-weakening distance on earthquake faults by using a new approach, which is independent of the estimate of fracture energy or radiated seismic energy. The approach is to find a physically based relation between the breakdown time of shear stress $T_{\mathrm{b}}$, the time of peak slip-velocity $T_{\mathrm{pv}}$, and the slip-weakening distance $D_{\mathrm{c}}$, from the time histories of shear stress, slip, and slip velocity at each point on the fault, which can be obtained from dynamic rupture calculations using a simple slip-weakening friction law. Numerical calculations are carried out for a dynamic shear crack propagating either spontaneously or at a fixed rupture velocity on a vertical fault located in a 3D half-space and a more realistic horizontally layered structure, with finite-difference schemes. The results show that $T_{\mathrm{pv}}$ is well correlated with $T_{\mathrm{b}}$ for faults even with a heterogeneous stress-drop distribution, except at locations near strong barriers and the fault edges. We also investigate this relation for different types of slip-weakening behavior.

We have applied the method to two recent, strike-slip earthquakes in western Japan, the 2000 Tottori and the 1995 Kobe events. We integrated the slip-velocity functions on the vertical fault obtained from kinematic waveform inversion of strongmotion and teleseismic records from the arrival time of rupture $T_{\mathrm{r}}$ to the time of the peak-slip velocity $T_{\mathrm{pv}}$, and we then corrected the slip obtained at $T_{\mathrm{pv}}$ for the errors expected from the dynamic calculations. It was found that the slip-weakening distance $D_{\mathrm{c}}$ estimated in the frequency window between 0.05 and $0.5 \mathrm{~Hz}$ ranges between 40 and $90 \mathrm{~cm}$ on the two earthquake faults. However, if we consider the limited frequency resolution of the observed waveforms, probable time errors in the slipvelocity functions obtained from kinematic inversion, and the uncertainty of the slipweakening behavior, the above estimates may be those located between the minimum resolvable limit and the upper bound of their real values. The estimated $D_{\text {c }}$ values do not necessarily seem to indicate larger values in the shallower part and smaller values in the deeper part of the fault, but rather a spatially heterogeneous distribution that appears to be dependent on the local maximum slip. This possible dependence might be interpreted by the frictional properties of the fault such as the degree of roughness or the thickness of gouge layers, in addition to stress heterogeneities.
\end{abstract}

\section{Introduction}

It is now widely accepted that the earthquake source can be modeled by shear rupture propagating on a pre-existing or newly created fault embedded in the earth's crust or upper mantle. The rupture is thought to initiate quasi-statically at a small nucleation zone and then develop into an unstable, dynamic phase over the fault plane. The rupture process may be controlled not only by the stress distribution on and

*Present address: Institute of Seismology and Earthquake Engineering, Building Research Institute, Tsukuba, Ibaraki 305-0802, Japan; yagi@kenken.go.jp. around the fault zone but also by the frictional properties of the fault surface. An increasing number of studies have recognized that the constitutive relation on the fault, particularly the slip-dependent weakening of shear stress, plays a critical role in the dynamic part of the rupture process and hence on strong ground motions during large earthquakes.

The concept of slip-weakening behavior was first introduced by Ida (1972) and Palmer and Rice (1973) into shear crack models to remove the well-known mathematical singularity at the propagating crack tip, by assuming the existence of a cohesive zone just behind the rupture front. Al- 
though Ida (1972) assumed several types of behavior, it was idealized by Andrews (1976a,b) as a simple slip-weakening model, as shown in Figure 1, where the initial stress $\sigma_{0}$ at each point on a $2 \mathrm{D}$ fault increases up to the yield stress $\sigma_{\mathrm{y}}$ as the rupture front approaches, and then decreases linearly with ongoing slip to the residual friction or dynamic friction level $\sigma_{\mathrm{f}}$. The slip at $\sigma_{\mathrm{f}}$ is defined as the critical weakening slip or slip-weakening distance $D_{\mathrm{c}}$, and the effective surface energy $G$ to be the work done is defined as fracture energy $G=\left(\sigma_{\mathrm{y}}-\sigma_{\mathrm{f}}\right) D_{\mathrm{c}} / 2$. This model was extended by Day (1982) into the fault in a 3D homogeneous whole-space and later applied in a number of theoretical studies and dynamic numerical simulations using various frictional conditions (e.g., Ohnaka and Yamashita, 1989; Matsu'ura et al., 1992; Shibazaki and Matsu'ura, 1992, 1998; Fukuyama and Madariaga, 1995, 1998, 2000; Tullis, 1996; Madariaga et al., 1998; Madariaga and Olsen, 2000; Campillo et al., 2001). Among these studies, Ohnaka and Yamashita (1989) proposed a slip-weakening behavior based on laboratory experiments, whereas Matsu'ura et al. (1992) presented several slip-strengthening and slip-weakening relations based on a physical model that was derived from frictional resistance due to microscopic interactions between statistically selfsimilar fault surfaces with different wavelength of roughness. Campillo et al. (2001) also provided effective slipweakening laws for heterogeneous fault surfaces with several barriers.

These conceptual models of slip weakening are now supported by experimental evidence on rock materials (e.g., Dieterich, 1981; Okubo and Dieterich, 1984; Ohnaka et al., 1987; Scholz, 1988; Ohnaka and Kuwahara, 1990; Dieterich and Kilgore, 1996; Ohnaka, 1996; Ohnaka and Shen, 1999). Some of these laboratory experiments (Dieterich, 1981; Ohnaka and Kuwahara, 1990) provided the time histories of stress, slip, and slip velocity, depicting the breakdown time of stress with the order of $1 / 10 \mathrm{msec}$ and the corresponding $\mathrm{D}_{\mathrm{c}}$ in the range from a few to several $\mu \mathrm{m}$. Another important finding from the experiments is that $D_{\mathrm{c}}$ is closely related to the characteristic wavelength of the roughness of the fault surface (Ohnaka and Kuwahara, 1990; Ohnaka and Shen, 1999) and also controlled by the thickness of fault gouge layers (Marone and Kilgore, 1993). On the other hand, another class of a rate- and state-dependent friction law was proposed by Dieterich $(1979,1981)$ and Ruina $(1993)$, based on extremely low slip-rate experiments on frictional sliding. Although this friction law will dominate at an early stage of the quasi-static process in a nucleation zone (e.g., Dieterich and Kilgore, 1996), at a stress recovery process on the fault and during the earthquake cycle, the dynamic rupture process with much higher slip velocities may not be controlled by this law but rather by the slip-dependent behavior (e.g., Okubo and Dieterich, 1984; Kato and Tullis, 2001).

For actual earthquakes, several attempts have been made to date to infer the slip-weakening distance $D_{\mathrm{c}}$. An earlier study of Papageorgiou and Aki (1983) estimated $D_{\mathrm{c}}$ to be in the range between 40 and $400 \mathrm{~cm}$ from acceleration

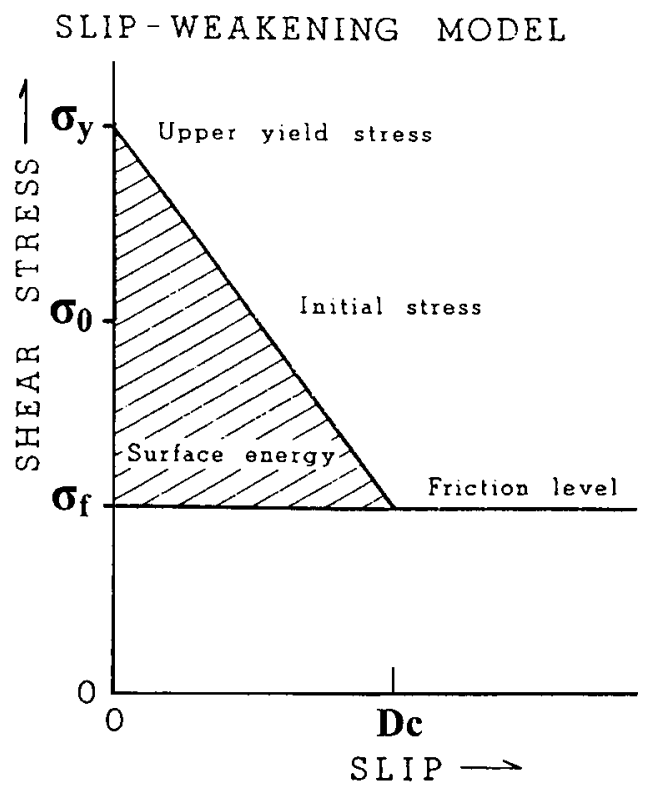

Figure 1. Linear slip-weakening friction law, modified from Andrews (1976a,b). $\sigma_{\mathrm{y}}$, yield stress; $\sigma_{0}$, initial stress; $\sigma_{\mathrm{f}}$, residual frictional stress; $D_{\mathrm{c}}$, critical slip-weakening distance.

spectra for several California earthquakes on the basis of their specific barrier model, although these estimates were later refined to the range from 20 to $150 \mathrm{~cm}$ (Aki and Papageorgiou, 1987). More recently, Ide and Takeo (1997) used the results from kinematic waveform inversion of strong-motion records obtained during the 1995 Kobe earthquake and found that $D_{\mathrm{c}}$ ranges between 50 and $100 \mathrm{~cm}$ for deeper fault sections and between 100 and $150 \mathrm{~cm}$ for shallower fault sections. Olsen et al. (1997) and Peyrat et al. (2001) also found $D_{\mathrm{c}}$ on the order of $80 \mathrm{~cm}$ from waveform inversion of the accelerograms observed during the 1992 Landers earthquake, with spontaneous dynamic rupture models. Day et al. (1998) also calculated the time histories of dynamic shear stress change on the fault, from kinematic slip models of three recent earthquakes, but the stress change was rather gradual, probably due to the limited resolution in the underlying kinematic inversions. On the other hand, Guatteri and Spudich (2000) claimed that strong-motion waveforms from the 1979 Imperial Valley earthquake could not resolve two rupture models having similar fracture energy, with $D_{\mathrm{c}}=30 \mathrm{~cm}$ and high strength excess and with $D_{\mathrm{c}}=100 \mathrm{~cm}$ and low strength excess, in the $0-$ to $1.6-\mathrm{Hz}$ frequency range. Pulido and Irikura (2000) used the spatiotemporal distribution of apparent stress calculated from slipvelocity functions on the fault and estimated $D_{\mathrm{c}}$ to range between 100 and $350 \mathrm{~cm}$ for the 1992 Landers earthquake. Ohnaka (2000) calculated $D_{\mathrm{c}}$ from a relation between the critical size of the nucleation zone and the breakdown stress drop mainly for the observed data of slow initial phase given by Ellsworth and Beroza (1995) for a number of earthquakes 
with different magnitudes, their values ranging between 1 and $300 \mathrm{~cm}$.

It seems, however, that some of the $D_{\mathrm{c}}$ values may be overestimated due to limited data resolution and may furthermore be biased by computational constraints, although we believe that $D_{\mathrm{c}}$ may be a significant fraction of the maximum slip on the fault. There also remains a question as to what extent $D_{\mathrm{c}}$ scales with the size of the fault zone and hence with the earthquake size (Marone and Kilgore, 1993), whereas its scale effect has been suggested for natural faults (Scholz and Aviles, 1986), from laboratory experiments (Okubo and Dieterich, 1984; Ohnaka and Shen, 1999), and from synthetic data (Ohnaka, 2000).

In the present study, we use a simple, new approach to estimate the slip-weakening distance $D_{\mathrm{c}}$ from strong-motion records, independently from the estimate of the fracture energy or radiated seismic energy. The motivation of our method comes from the time histories of stress, slip, and slip velocity obtained in laboratory experiments (Dieterich, 1981; Ohnaka and Kuwahara, 1990), suggesting that the first pulse width of slip acceleration on the fault surface is closely related to the local stress breakdown time (Ohnaka and Yamashita, 1989; Shibazaki and Matsu'ura, 1998). Another motivation is the clearly different shapes of the slip-velocity time histories on the fault for different slip-weakening distances (Guatteri and Spudich, 2000). As we will mention later, our method requires high resolution in the time domain both in the kinematic and dynamic slip-velocity functions on the fault. We apply this method to estimate $D_{\mathrm{c}}$ in the frequency range between 0.05 and $0.5 \mathrm{~Hz}$ for two recent, vertical strike-slip earthquakes, that is, the 2000 Tottori and 1995 Kobe earthquakes in western Japan.

\section{Dynamic Rupture Modeling}

In order to estimate the slip-weakening distance $D_{\mathrm{c}}$ on actual earthquake faults, we perform, as a first step, numerical experiments for dynamic shear cracks propagating either spontaneously or at a fixed rupture velocity on a vertical fault located in a $3 \mathrm{D}$ half-space or a more realistic horizontally layered structure. From these calculations under various conditions, we find a physically based relation between the breakdown time of shear stress $T_{\mathrm{b}}$, the time of peak slipvelocity $T_{\mathrm{pv}}$, and the prescribed slip-weakening distance $D_{\mathrm{c}}$, at each point on the $2 \mathrm{D}$ fault. $T_{\mathrm{b}}$ is the time when the shear stress drops to the level of the residual frictional stress, at which the ongoing slip reaches $D_{\mathrm{c}}$, but cannot be directly inferred from seismic observations. Instead, $T_{\mathrm{pv}}$ should, in principle, be slightly different from $T_{\mathrm{b}}$, and it is, on the other hand, an observable parameter. The slip at $T_{\mathrm{pv}}$ is denoted here as $D_{\mathrm{c}}{ }^{\prime}$. Based on such a relation, it is possible to use $T_{\mathrm{pv}}$ observed from kinematic waveform inversion of strongmotion records from an earthquake in order to estimate $D_{\mathrm{c}}$ after correcting $T_{\mathrm{pv}}$ for $T_{\mathrm{b}}$. For this purpose, we solve the 3D elastodynamic equations using appropriate boundary con- ditions with finite-difference schemes, as described in a following section.

\section{Theoretical Considerations}

The validity of our method may be justified from the theoretical background (Fukuyama et al., 2002) described below. The shear traction on a $2 \mathrm{D}$ fault in a homogeneous elastic medium has been expressed by Fukuyama and Madariaga (1998) using boundary integral equations in the following form,

$$
\begin{aligned}
& \sigma\left(x_{1}, x_{2}, t\right)=-\mu V\left(x_{1}, x_{2}, t\right) / 2 \beta \\
& \quad+\int_{\mathrm{S}} \int_{0}^{t} K\left(x_{1}, x_{2}, t \mid \xi_{1}, \xi_{2}, \tau\right) V\left(\xi_{1}, \xi_{2}, \tau\right) d \tau d \xi_{1} d \xi_{2}
\end{aligned}
$$

where $\sigma$ and $V$ are the shear stress and slip velocity, $K$ is the kernel related to the slip history, $\mu$ and $\beta$ are the rigidity and shear-wave velocity in the medium, respectively. A more detailed expression of $K$ is given by Fukuyama and Madariaga (1998). The first term is proportional to the current slip velocity, whereas the second term is the contribution from the past slip history in space and time. When the total stress $\sigma$ drops to the level of the residual stress at $T_{\mathrm{b}}$, and if the second term changes smoothly around this time, then we expect that the slip velocity in the first term would reach its peak at that time. Figure 2 shows one of numerical examples of the calculated stress history (Fukuyama et al., 2002) for the linear slip-weakening behavior as given by Andrews (1976a,b), near the center of a fault with a dimension of $25.6 \mathrm{~km} \times 12.8 \mathrm{~km}$, being subjected to a uniform stress drop of $3.5 \mathrm{MPa}$ and a prescribed slip-weakening distance of $D_{\mathrm{c}}=70 \mathrm{~cm}$. As expected, the contribution from the sec-

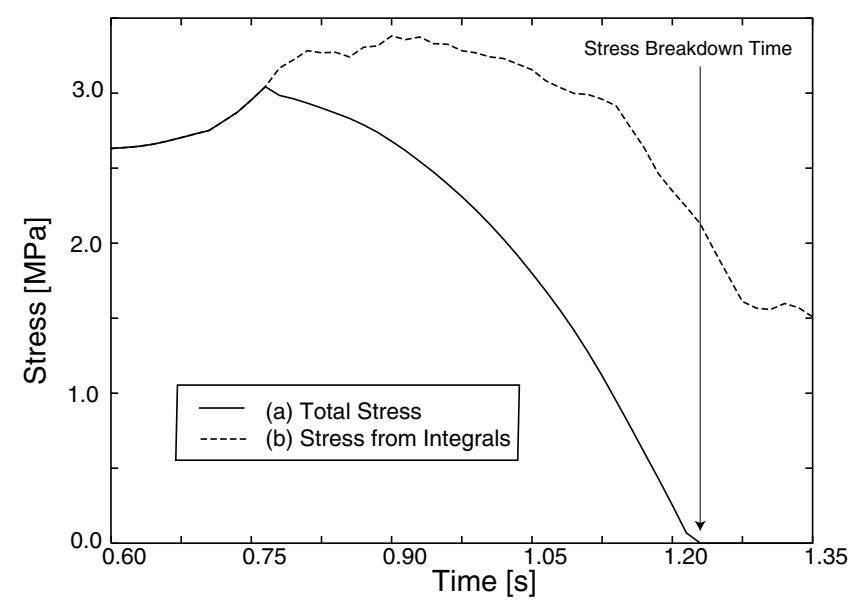

Figure 2. Time history of stress changes near the center of a homogeneous fault subjected to a uniform stress drop of $3.5 \mathrm{MPa}$ and $D_{\mathrm{c}}=70 \mathrm{~cm}$. The fault dimension is $25.6 \mathrm{~km} \times 12.8 \mathrm{~km}$ with a grid size of $0.2 \mathrm{~km} \times 0.2 \mathrm{~km}$, and the time increment is taken as $0.015 \mathrm{sec}$, in this calculation. (a) Total stress, (b) stress contribution from past slip in space and time (Fukuyama et al., 2002). 
ond term changes smoothly around the breakdown time $T_{\mathrm{b}} \sim 1.22 \mathrm{sec}$ of the total stress $\sigma$, indicating that our technique should work well at this point.

However, if the integral term changes rapidly near the edges of the fault or near strong barriers, where a stopping phase will be generated due to abrupt change in the rupture velocity, the time of peak slip-velocity $T_{\mathrm{pv}}$ will deviate from $T_{\mathrm{b}}$ to some extent. Fukuyama et al. (2002) provided several examples of the time histories of the stress, slip velocity, and slip calculated from dynamic rupture propagating on a fault with barriers and asperities and concluded that the present technique works properly except for the case in front of strong barriers.

\section{Method of Numerical Calculations}

First, we simulate a dynamic shear crack on a vertical fault in a 3D homogeneous half-space (Miyatake, 1980) and in a horizontally layered structure (Mikumo et al., 1987; Mikumo and Miyatake, 1995), which is subjected to the shear stress working parallel to the strike direction. The dynamic rupture propagation over the vertical fault can be calculated by solving the elastodynamic equation, incorporating the slip-weakening friction together with appropriate boundary conditions. The slip-weakening condition introduced here is

$$
\begin{array}{r}
\sigma(D)=\sigma_{\mathrm{y}}-\left(\sigma_{\mathrm{y}}-\sigma_{\mathrm{f}}\right) D / D_{\mathrm{c}} \text { for } D<D_{\mathrm{c}}, \\
\text { and } \sigma(D)=\sigma_{\mathrm{f}} \text { for } D>D_{\mathrm{c}}
\end{array}
$$

for $\sigma_{\mathrm{f}}<\sigma_{0}<\sigma_{\mathrm{y}}$, following Andrews (1976a,b), where $D$ is the current slip displacement. The stress change for $D<D_{\text {c }}$ relative to the initial stress $\sigma_{0}$ may also be written as

$$
\Delta \sigma(D)=\left(\sigma_{\mathrm{y}}-\sigma_{0}\right)\left(1-D / D_{\mathrm{c}}\right)-\left(\sigma_{0}-\sigma_{\mathrm{f}}\right) D / D_{\mathrm{c}},
$$

where $\sigma_{\mathrm{y}}-\sigma_{0}$ is called the strength excess, and $\sigma_{0}-\sigma_{\mathrm{f}}$ is the dynamic stress drop. The boundary conditions imposed here are (1) the continuity of the normal stress and normal displacement across the vertical fault, (2) traction-free vertical stress at the ground surface, (3) the continuity of all stress and displacement components at each of the layer interfaces in case of a horizontally layered structure (Mikumo et al., 1987), and (4) absorbing boundary conditions at the sides and bottom of the model space (Clayton and Engquist, 1977). The radius of the nucleation zone for dynamic rupture in the $3 \mathrm{D}$ case is given as

$$
R_{\mathrm{c}}=(7 \pi / 24) \mu D_{\mathrm{c}}\left(\sigma_{\mathrm{y}}-\sigma_{\mathrm{f}}\right) /\left(\sigma_{0}-\sigma_{\mathrm{f}}\right)^{2}
$$

(Day, 1982). To initiate dynamic rupture, the initial stress is taken as $\sigma_{\mathrm{f}}$ or a small preslip is prescribed within this zone. The rupture is assumed to propagate at a fixed velocity equivalent to $70 \%$ of the $S$-wave velocity in each layer, in second-order finite difference calculations. This case is referred to as a quasi-dynamic rupture.
We also solve our problem by a fourth-order staggeredgrid finite difference scheme for spontaneous rupture propagation, which was first introduced by Madariaga (1976) and later developed by Virieux (1986), Levander (1988), and particularly by Olsen (1994), Olsen et al. (1995), Olsen and Archuleta (1996), and Madariaga et al. (1998). This scheme solves the 3D elastodynamic equations through the velocitystress formulations, using a fourth-order approximation to spatial derivatives and a second-order approximation to time derivatives. In this scheme, stresses and velocities are computed at alternating half-integer time step and at half-integer grid spacing but have appropriate symmetries with respect to the fault plane (Madariaga et al., 1998). A free-surface boundary condition is included at the top and sponge layers, in addition to absorbing boundary condition at the remaining grid boundaries (Madariaga et al., 1998). This method also incorporates the slip-weakening friction law given in equation (2), where $\sigma_{\mathrm{f}}$ is taken to be 0 for simplicity. Dynamic rupture is initiated by reducing the yield stress $\sigma_{\mathrm{y}}$ to 0 in the nucleation zone around the hypocenter, followed by spontaneous propagation. The numerical and dynamic parameters used in the second- and fourth-order finite-difference calculations are listed in Table 1, and the crust and uppermantle velocity structures adopted here are listed in Tables 2 and 3.

\section{Numerical Results for a Homogeneous Fault}

We tested our method for a uniformly loaded vertical fault in a homogeneous medium using the quasi-dynamic finite-difference scheme. The slip-weakening distance was $20 \mathrm{~cm}$, and the prescribed stress drop was $2 \mathrm{MPa}$. Figure 3 shows a typical behavior of the time histories of shear stress, slip, and slip velocity at a location on the fault. It should be noticed that the slip and slip velocity start to evolve as the shear stress increases due to the arrival of the rupture front and that the slip velocity rapidly increases as the stress drops from its yield value and then reaches the peak value at time $T_{\mathrm{pv}}$. However, $T_{\mathrm{pv}}$ deviates slightly from the stress-breakdown time $T_{\mathrm{b}}$, and the slip $D_{\mathrm{c}}{ }^{\prime}$ at time $T_{\mathrm{pv}}$ is somewhat different from the prescribed slip-weakening distance $D_{\mathrm{c}}$ at time $T_{\mathrm{b}}$.

The calculations show that the $\operatorname{sip} D_{\mathrm{c}}{ }^{\prime}$ at time $T_{\mathrm{pv}}$ at a number of selected points on the fault scatters between 14 and $26 \mathrm{~cm}$ around the prescribed value of $20 \mathrm{~cm}$ (not shown here), suggesting that the slip-weakening distance in this case can be recovered with an error of less than $30 \%$ from the measurement of the time of the peak slip-velocity. The rather large deviations arise mainly from the points closer to the edges of the fault. For heterogeneous cases, we will show similar test results in the section $T_{\mathrm{b}}-T_{\mathrm{pv}}-D_{\mathrm{c}}{ }^{\prime}$ Relations for two models (Figs. 4, 5) for the Tottori earthquake.

\section{Application to Two Strike-Slip Earthquakes}

Now, we apply our method to two recent, strike-slip earthquakes that occurred on near-vertical faults in order to 
Table 1

Parameters for 3D Dynamic Modeling

\begin{tabular}{lccc}
\hline & & $1^{*}$ & $2^{\dagger}$ \\
\hline Model dimension & $(\mathrm{km})$ & $46 \times 35 \times 25$ & $100 \times 90 \times 50 / 120 \times 80 \times 50$ \\
Grid spacing & $(\mathrm{km})$ & 0.25 & $1.0 / 0.5$ \\
Time increment & $(\mathrm{sec})$ & 0.0125 & $0.05 / 0.025$ \\
Fault dimension & $(\mathrm{km})$ & $25 \times 15(0-15)$ & $24 \times 15(1-16)$ \\
Yield stress & $(\mathrm{MPa})$ & 10 & $($ estimated) \\
$D_{\mathrm{c}}$ (prescribed) & $(\mathrm{cm})$ & $20,30,70$ & $10,20,30,40$ \\
Rupture velocity & & (spontaneous) & $0.70 \beta$ \\
\hline
\end{tabular}

\footnotetext{
*Spontaneous dynamic rupture calculations with a fourth-order staggered-grid finite-difference scheme.

${ }^{\dagger}$ Quasi-dynamic rupture calculations with a second-order finite-difference scheme. Numerals in parentheses indicate the fault depth range, $\beta$ is the $S$-wave velocity, $V_{s}$, in each layer (Table 2).
}

Table 2

Crustal Structure for the Tottori Region* Used in the Dynamic Rupture Calculations with Yagi's (2001) Model

\begin{tabular}{ccccc}
\hline Layer No. & $H(\mathrm{~km})$ & $V_{p}(\mathrm{~km} / \mathrm{sec})$ & $V_{\mathrm{s}}(\mathrm{km} / \mathrm{sec})$ & $\rho\left(\mathrm{g} / \mathrm{cm}^{3}\right)$ \\
\hline 1 & 0 & 5.50 & 3.18 & 2.68 \\
2 & 2 & 6.05 & 3.50 & 2.80 \\
3 & 17 & 6.60 & 3.82 & 2.90 \\
4 & 32 & 8.00 & 4.02 & 3.20 \\
\hline
\end{tabular}

*Shibutani et al. (2001).

Table 3

Crustal Structure for the Tottori Region Used in the Dynamic Calculations with the Fukuyama-Dreger Model

\begin{tabular}{ccccc}
\hline Layer No. & $H(\mathrm{~km})$ & $V_{\mathrm{p}}(\mathrm{km} / \mathrm{sec})$ & $V_{\mathrm{s}}(\mathrm{km} / \mathrm{sec})$ & $\rho\left(\mathrm{g} / \mathrm{cm}^{3}\right)$ \\
\hline 1 & 0 & 5.50 & 3.14 & 2.30 \\
2 & 3 & 6.00 & 3.55 & 2.40 \\
\hline
\end{tabular}

$H$, depth to top of layer; $V_{p}, P$-wave velocity; $V_{s}, S$-wave velocity; $\rho$, density.

evaluate the slip-weakening distance using the distributions of fault slip and stress change derived primarily from strong ground motions recorded at near-source stations.

\section{The 2000 Tottori Earthquake}

The Tottori earthquake $\left(M_{\mathrm{w}} 6.6\right)$ occurred in the western Tottori region, western Honshu, Japan, on 6 October 2000. The hypocenter of the mainshock was located at $35.27^{\circ} \mathrm{N}$ and $133.35^{\circ} \mathrm{E}$ at a depth of $11 \mathrm{~km}$ (Japan Meterological Agency, [JMA]). The centroid moment tensor (CMT) solutions from regional data and the focal mechanism solution from local data consistently provided a purely strike-slip mechanism for this earthquake (Fukuyama et al., 2001; Shibutani et al., 2001). Observations from local high-resolution stations revealed that many aftershocks were distributed over a length of about $25-30 \mathrm{~km}$ in the $\mathrm{N} 27^{\circ}-30^{\circ} \mathrm{W}$ direction at depths between 1 and $15 \mathrm{~km}$ (Shibutani et al., 2001), although this distribution was extended some days later toward the northwest direction, and a separate group of aftershocks occurred about $25 \mathrm{~km}$ westward in a direction parallel to the main distribution. This direction agrees with the strike of one of the nodal planes determined from the CMT solutions.

The mainshock has been well recorded at a number of near-source strong-motion stations, the K-NET and KiK-net operated by the National Research Institute for Earth Sciences and Disaster Prevention (NIED), regional broadband stations, and teleseismic stations. Until now, three different source models have been obtained from kinematic inversion: by E. Fukuyama and D. S. Dreger (unpublished manuscript, 2001) from regional broadband seismic waveforms, by Yagi (2001) from near-source strong-motion data and teleseismic waveforms, and by Iwata and Sekiguchi (2001) from nearsource strong-motion records and Global Positioning System (GPS) and leveling data. In our study, we refer to Yagi's (2001) slip model to estimate the dynamic parameters, with some reference to the models of Fukuyama and Dreger (2001) and Iwata and Sekiguchi (2001).

\section{$T_{\mathrm{b}}-T_{\mathrm{pv}}-D_{\mathrm{c}}{ }^{\prime}$ Relations}

We have made calculations for the $T_{\mathrm{b}}-T_{\mathrm{pv}}-D_{\mathrm{c}}{ }^{\prime}$ relations for the following two models, both of which include nonuniform slip distributions and hence heterogeneous stress drop (not shown here). One of the quasi-dynamic calculations is for an early version of Yagi's (2001) model (version 0 ) with $D_{\mathrm{c}}=30 \mathrm{~cm}$ for a fault with a dimension of $24 \mathrm{~km}$ $\times 16 \mathrm{~km}$ located in the layered velocity structure defined in Table 2. Comparing the time histories of stress, slip, and slip velocity (not shown) with those for the homogeneous fault, the shear stress drops rather rapidly and the slip-velocity functions yield narrower pulse widths. This can be explained by short scale-length, stress-drop heterogeneities, as has been pointed out by Beroza and Mikumo (1996). Figure 4 shows the $T_{\mathrm{b}}-T_{\mathrm{pv}}$ relation at the right-hand side and the $T_{\mathrm{pv}}-D_{\mathrm{c}}{ }^{\prime}$ relation at the left-hand side for several selected points aligned in the strike and dip directions from the rupture starting point. In this case $D_{\mathrm{c}}{ }^{\prime}$ falls between 20 and 38 $\mathrm{cm}$ except for one point, suggesting that the slip-weakening distance may be recovered again with an error of $30 \%$.

For comparison, we also estimated the $T_{\mathrm{b}}-T_{\mathrm{pv}}-D_{\mathrm{c}}{ }^{\prime}$ relation for the Fukuyama and Dreger's model (2001), which includes a vertical fault with a dimension of $25 \mathrm{~km} \times 15$ 


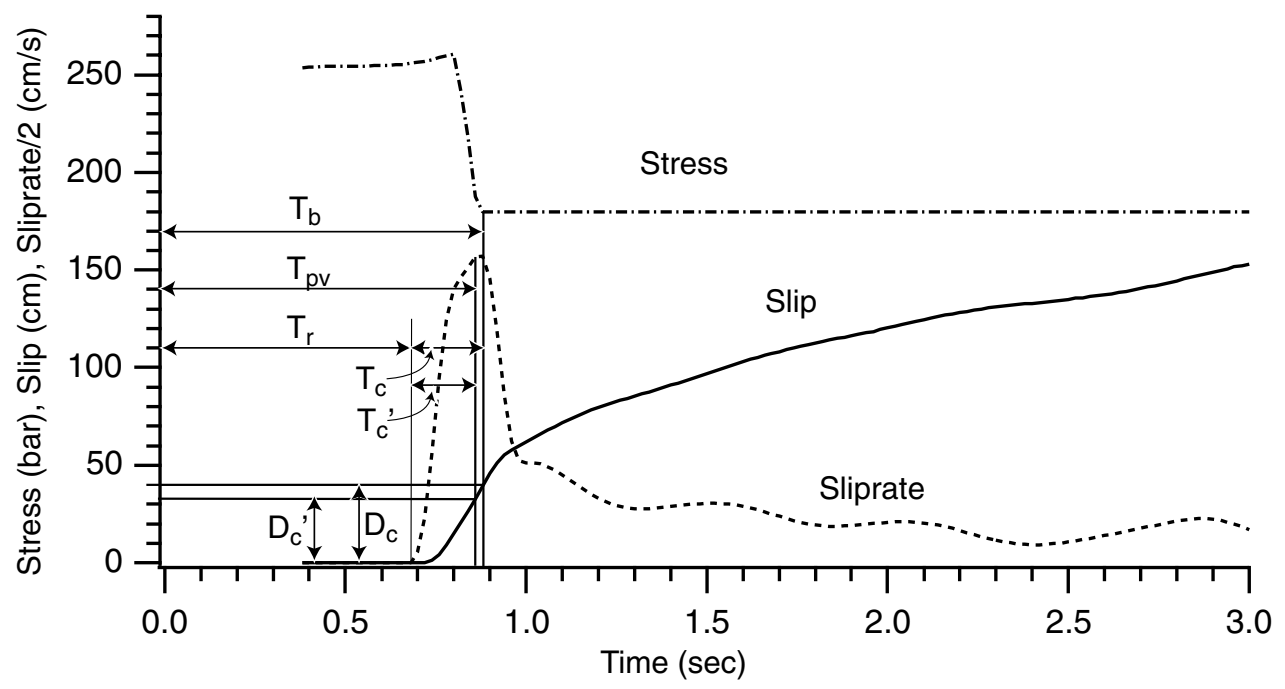

Figure 3. A typical behavior of the time history of shear stress, slip, and slip velocity on the fault. $T_{\mathrm{b}}$, breakdown time of stress; $T_{\mathrm{pv}}$, time of peak slip-velocity; $D_{\mathrm{c}}$, slip at time $T_{\mathrm{b}} ; D_{\mathrm{c}}{ }^{\prime}$, slip at time $T_{\mathrm{pv}}$.
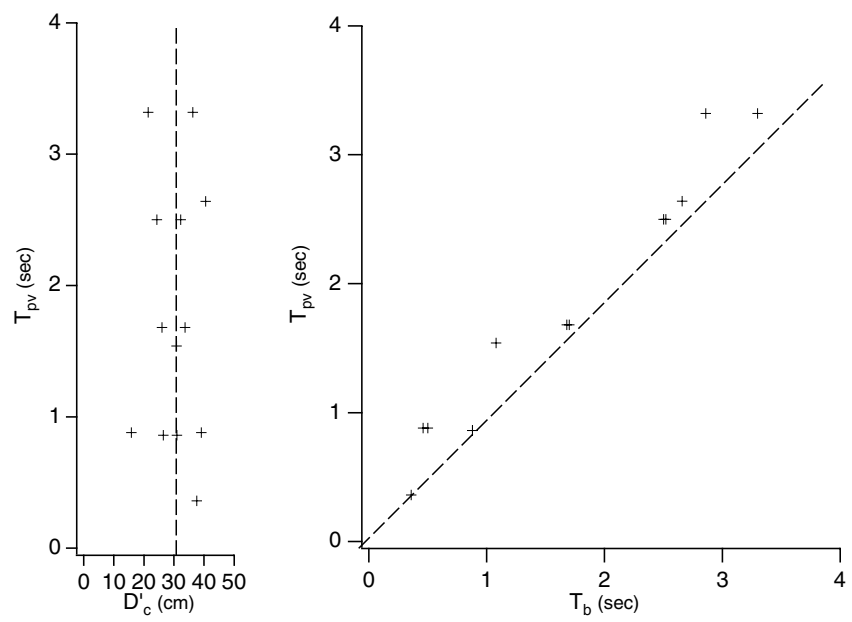

Figure 4. Relation between $T_{\mathrm{pv}}$ and $T_{\mathrm{b}}$ (right) and between $D_{\mathrm{c}}{ }^{\prime}$ and $T_{\mathrm{pv}}$ (left) for a heterogeneous fault with a prescribed value of $D_{\mathrm{c}}=30 \mathrm{~cm}$ in Yagi's preliminary slip model (2001) for the Tottori earthquake. $T_{\mathrm{b}}$ and $T_{\mathrm{pv}}$ are measured from the time at the rupture starting point.

$\mathrm{km}$ located in the velocity structure listed in Table 3. The fault is subjected to a yield stress of $10 \mathrm{MPa}$, a prescribed slip-weakening distance of $70 \mathrm{~cm}$, and an assumed tectonic stress of 4.25 $\mathrm{MPa}$. The rupture was started artificially at a depth of $11 \mathrm{~km}$ in the middle of the fault length. Figure 5 shows the relations between $T_{\mathrm{b}}$ and $T_{\mathrm{pv}}$ and between $T_{\mathrm{pv}}$ and $D_{\mathrm{c}}{ }^{\prime}$ for 49 points nearly evenly distributed on the fault, calculated from the stress, slip, and slip-velocity functions obtained by a fourth-order accurate finite-difference method. We see that $T_{\mathrm{pv}}$ in this case is very well correlated with $T_{\mathrm{b}}$. $D_{\mathrm{c}}{ }^{\prime}$ estimated from $T_{\mathrm{pv}}$ ranges between 63 and $85 \mathrm{~cm}$, indicating that the slip-weakening distance can be retrieved within an error of $17 \%$. The deviation of $D_{\mathrm{c}}{ }^{\prime}$ exceeding $10 \%$ comes from several points near the upper fault edge and near the bottom corners of the fault. Later in this section, we will show the $T_{\mathrm{b}}-T_{\mathrm{pv}}-D_{\mathrm{c}}{ }^{\prime}$ relations for the Yagi's final model (version 1).

\section{Slip Distribution from Kinematic Waveform Inversion (Yagi's Model Version 1)}

Figure 6 shows the horizontal projection of the fault traces on the ground, the fault-plane solutions, and the distribution of near-source stations. Yagi (2001) carried out kinematic waveform inversion of 17 strong-motion records from the $6 \mathrm{~K}-\mathrm{NET}$ stations (Kinoshita, 1998) shown here and $10 P$-wave records from 10 teleseismic stations. The strong-motion data were bandpassed between 0.05 and 0.5 $\mathrm{Hz}$ and numerically integrated to ground velocity with a sampling time of $0.25 \mathrm{sec}$, whereas the teleseismic data were bandpassed between 0.01 and $0.8 \mathrm{~Hz}$ and converted to ground displacement with a sampling time of $0.25 \mathrm{sec}$. The frequency range has been adopted to remove low-frequency noise arising from the integration procedure and also because the Green's function is not known well enough at frequencies above $0.5 \mathrm{~Hz}$. We used a fourth-order butterworth filter. Yagi (2001) estimated the detailed spatiotemporal distribution of fault slip using a multi-time window inversion to all the data. For this inversion, the entire fault was divided into three segments, with 21 subfaults for FD1, 70 subfaults for FD2, and 14 subfaults for FD3, with dimensions of each subfault of $2 \mathrm{~km} \times 2 \mathrm{~km}$. The Green's functions for all subfault to strong-motion station pairs were calculated by the discrete wavenumber method developed by Koketsu (1985), while the functions for teleseismic stations were calculated by the method of Kikuchi and Kanamori (1991). The velocity structures used here are given in Tables 2 and 4, 

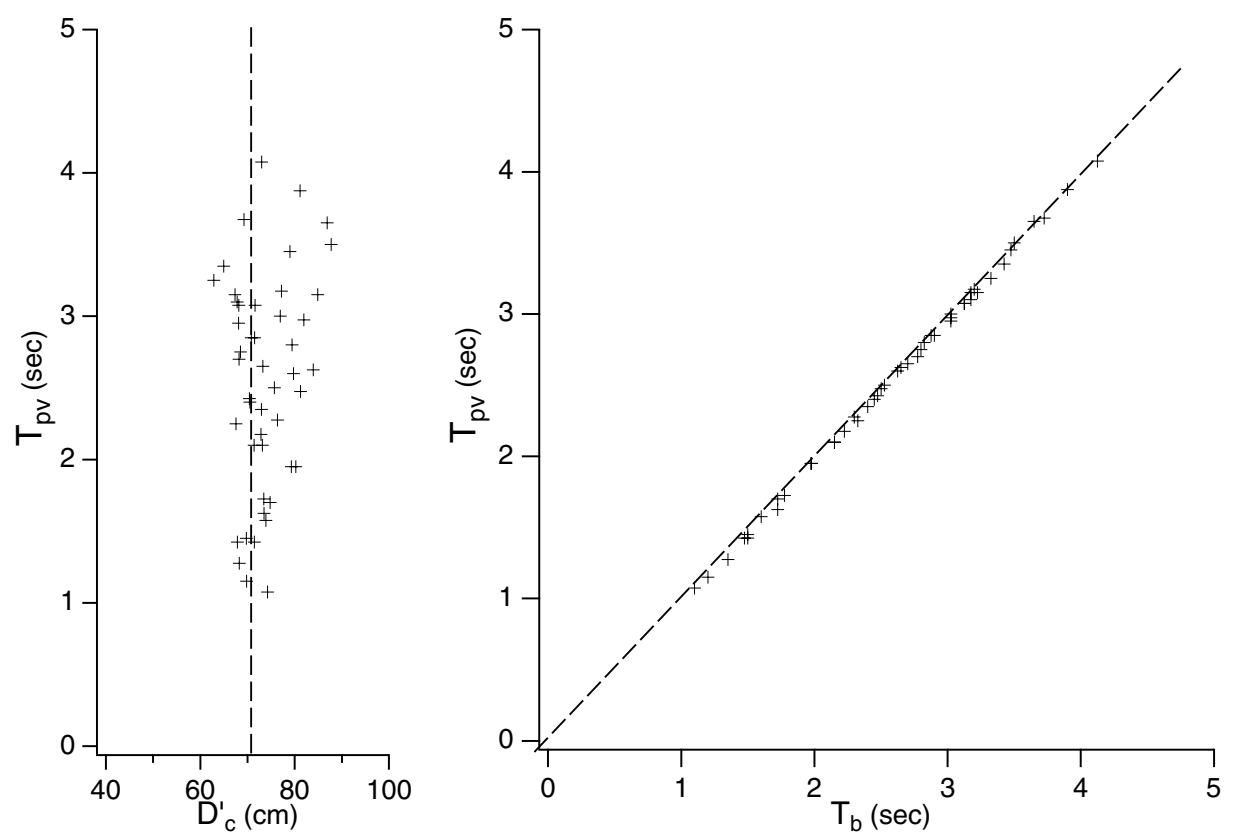

Figure 5. Same as Figure 3, but for a prescribed value of $D_{\mathrm{c}}=70 \mathrm{~cm}$ in Fukuyama and Dreger's slip model (2001).

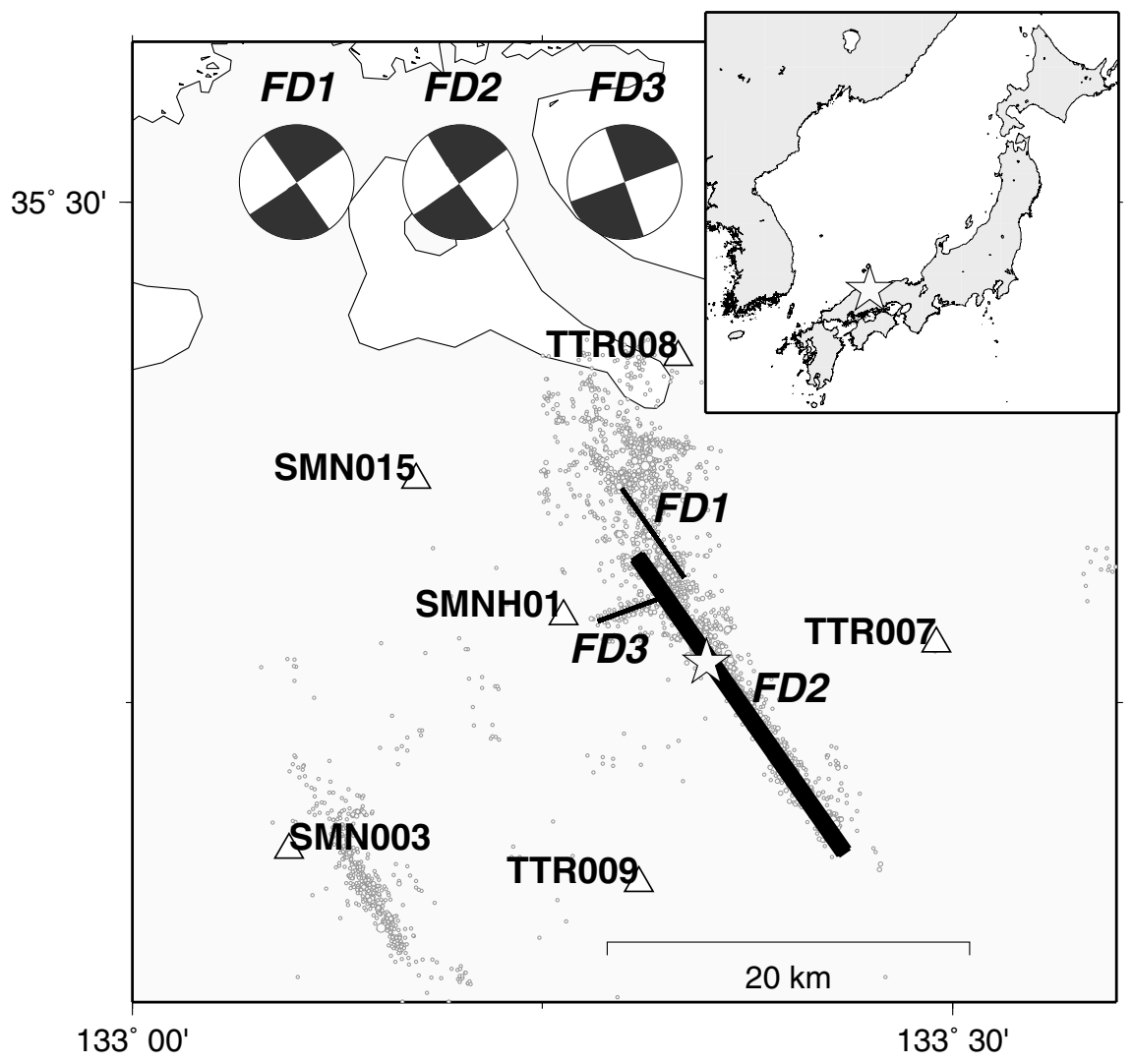

Figure 6. Location of the 2000 Tottori earthquake with the horizontal projection of three fault traces FD1, FD2, and FD3 inferred from the aftershock distribution, faultplane solutions, and near-source strong-motion stations (NIED). 
Table 4

Crust and Upper Mantle Structure Used for Teleseismic Receiver Stations (Yagi, 2001)

\begin{tabular}{ccccc}
\hline Layer No. & $H(\mathrm{~km})$ & $V_{p}(\mathrm{~km} / \mathrm{sec})$ & $V_{s}(\mathrm{~km} / \mathrm{sec})$ & $\rho\left(\mathrm{gr} / \mathrm{cm}^{3}\right)$ \\
\hline 1 & 0 & 5.57 & 3.36 & 2.65 \\
2 & 15 & 6.50 & 3.74 & 2.87 \\
3 & 33 & 8.10 & 4.68 & 3.30 \\
\hline
\end{tabular}

For Green's functions, the attenuation terms are included with $T / Q_{p}=$ $1.0(\mathrm{sec})$ and $T / Q_{s}=4.0(\mathrm{sec})$.

where we refer to Table 2 for near-source regions and Table 4 for the teleseismic receiver stations. The basis source time function on each subfault is expanded in 39 sequential overlapping triangles, each having a half duration of $0.25 \mathrm{sec}$ with a time shift of $0.25 \mathrm{sec}$, and resampled at an interval of $0.05 \mathrm{sec}$. To allow all subfaults to slip at any time, the start time of the source time function at all subfaults is set to $0 \mathrm{sec}$. All the observed records used here and the corresponding synthetic waveforms obtained from the final inversion are compared in Figure 7, generally showing a very good fit. Figure 8a shows a smoothed slip distribution on the two segments FD1 and FD2, which has been obtained from the final inversion. The slip on the southernmost subfault of FD1 and the northernmost subfault of FD2, which are parallel and partly overlap, are superimposed, and the segment FD3 is omitted. The maximum slip in the central fault section at a depth of about $6 \mathrm{~km}$ above the hypocenter reaches $2.3 \mathrm{~m}$, and the large values of slip exceeding $1.5 \mathrm{~m}$ are confined mainly in the upper fault section at depths between 3 and $9 \mathrm{~km}$ along strike distances between 6 and $21 \mathrm{~km}$.

\section{Spatial Distribution of Stress Changes}

Next, we calculate the spatial distribution of static stress change from the slip distribution shown in Figure 8a. The procedure follows the approach of Miyatake (1992) and Mikumo and Miyatake (1995). In this approach, local static stress changes at each point are derived by solving the static equilibrium equations in the 3D space, combined with the boundary conditions described in the section Dynamic Rupture Modeling. Given these static stress changes, we first calculate the slip from the dynamic rupture propagation and then take the ratio between the kinematic and dynamic slip at each point on the fault. The ratio is multiplied to the previously obtained static stress drop, and this procedure is repeated in an iterative, least-squares fashion until the rootmean-square (rms) difference between the kinematic and dynamic slip over the fault is minimized. For practical reasons, we interpolate the kinematic slip calculated at every $2 \mathrm{~km} \times 2 \mathrm{~km}$ subfaults (Fig. 8a) into $0.5 \mathrm{~km} \times 0.5 \mathrm{~km}$ subfaults.

Figure $8 \mathrm{~b}$ shows the spatial distribution of the calculated stress change. The maximum static stress drop corresponding to the maximum slip reaches 90 bars ( $9 \mathrm{MPa})$, and the stress drop in the zones of slip larger than $1.5 \mathrm{~m}$ is about 30 bars (3 MPa). At middepths near the west-northwest fault section and around the east-southeast fault edge and the shallowest section, there are zones of negative stress drop (stress increase). Thus, the stress change on the fault was found to be quite heterogeneous.

\section{Estimate of $D_{\mathrm{c}}$ from the Slip-Velocity Functions}

Figure 9 shows the slip-velocity time functions on all subfaults of the segment FD2, which were obtained at every $0.05 \mathrm{sec}$ in the final inversion to match the synthetics to the recorded waveforms. In order to estimate the slip-weakening distance through the procedure described in the foregoing sections, we numerically integrate the slip-velocity time functions from the time of the rupture arrival $T_{\mathrm{r}}$ to the time of the peak slip-velocity $T_{\mathrm{pv}}$ on each subfault, where $T_{\mathrm{r}}$ has been estimated within an error of $0.25 \mathrm{sec}$ from the inversion. The calculations are made only for selected slipvelocity functions that arrive at the time $T_{\mathrm{r}}$ and are not contaminated by minor spurious oscillations. The integration procedure provides $D_{\mathrm{c}}{ }^{\prime}$ at time $T_{\mathrm{pv}}$. The estimated values of $D_{\mathrm{c}}{ }^{\prime}$ are listed on the top of the slip-velocity function in each subfault in Figure 9.

To estimate the actual slip-weakening distance $D_{\mathrm{c}}$ from $D_{\mathrm{c}}{ }^{\prime}$, we made dynamic calculations with the spontaneous rupture finite-difference scheme for the heterogeneous fault, using the final slip and the stress change shown in Figure 8a and $b$ as the observational constraints. For practical reasons, we interpolated the spatial distributions into a grid spacing of $0.25 \mathrm{~km}$. The calculations were made for selected points (a, b, c, d, m, and n), for prescribed values of $D_{\mathrm{c}}=30 \mathrm{~cm}$ and $D_{\mathrm{c}}=70 \mathrm{~cm}$. Figure 10 shows an example of the calculated time histories of stress change, slip, and slip velocity at points $\mathrm{b}$ and $\mathrm{m}$. It is clear that for the case of $D_{\mathrm{c}}=70$ $\mathrm{cm}$ the stress drops more slowly and it takes a longer time for the slip rate to reach its peak than for the case of $D_{\mathrm{c}}=$ $30 \mathrm{~cm}$. Figure 11 shows the deviations of $T_{\mathrm{pv}}$ from $T_{\mathrm{b}}$ and those of $D_{\mathrm{c}}{ }^{\prime}$ from the prescribed values of $D_{\mathrm{c}}$ for the six selected points, where large slip-velocities have been obtained. From these results we find that correction factors $D_{\mathrm{c}}$ ' $D_{\mathrm{c}}{ }^{\prime}$ to be applied to the observed $D_{\mathrm{c}}{ }^{\prime}$ values are (a) 1.08 , (b) 0.96 , (c) 0.96 , (d) 1.00, (m) 1.00, and (n) 1.25. These factors differ from unity in less than $10 \%$ except for point $\mathrm{n}$ and are rather small as compared with the uncertainty described in the next section.

\section{Resolution of the Estimated $D_{\mathrm{c}}$ Values}

The resolution of $D_{\mathrm{c}}$ depends on the resolvable frequency involved in the observed records and also on how accurately $T_{\mathrm{pv}}$ can be estimated from these records. The resolution of $T_{\mathrm{pv}}$ is restricted by the bandwidth of the observed records and also by the sampling time interval of the calculated slip-velocity functions used in the kinematic inversion. As a first step, we estimate its minimum resolvable value $D_{\text {cmin }}$ tentatively following Guatteri and Spudich's expression (2000), which gives $D_{\text {cmin }}=V_{\mathrm{av}} T_{\text {cmin }}$, where $T_{\text {cmin }}$ is taken as the shortest modeled period involved in the ob- 

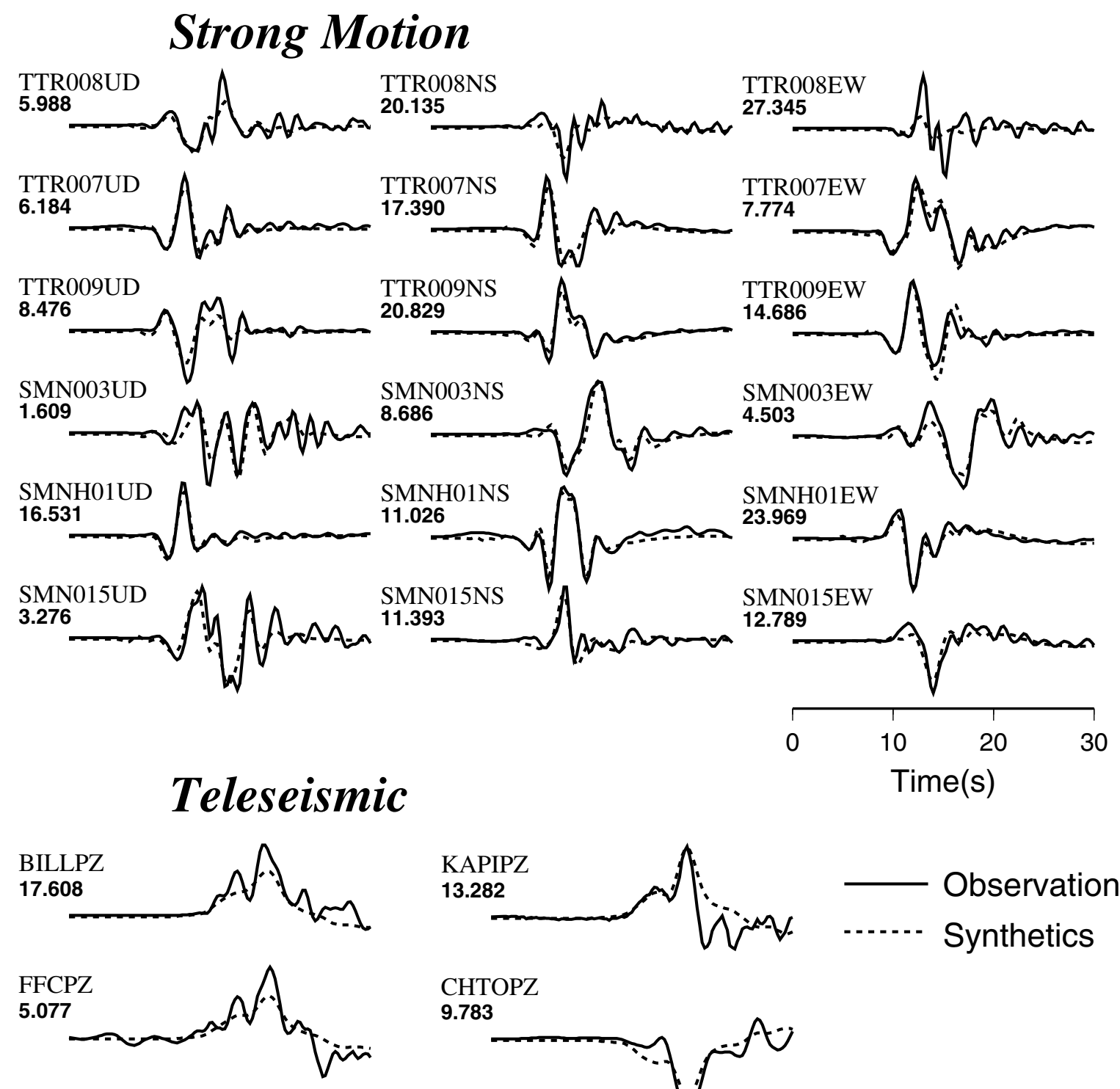

CHTOPZ
9.783

WAKEPZ
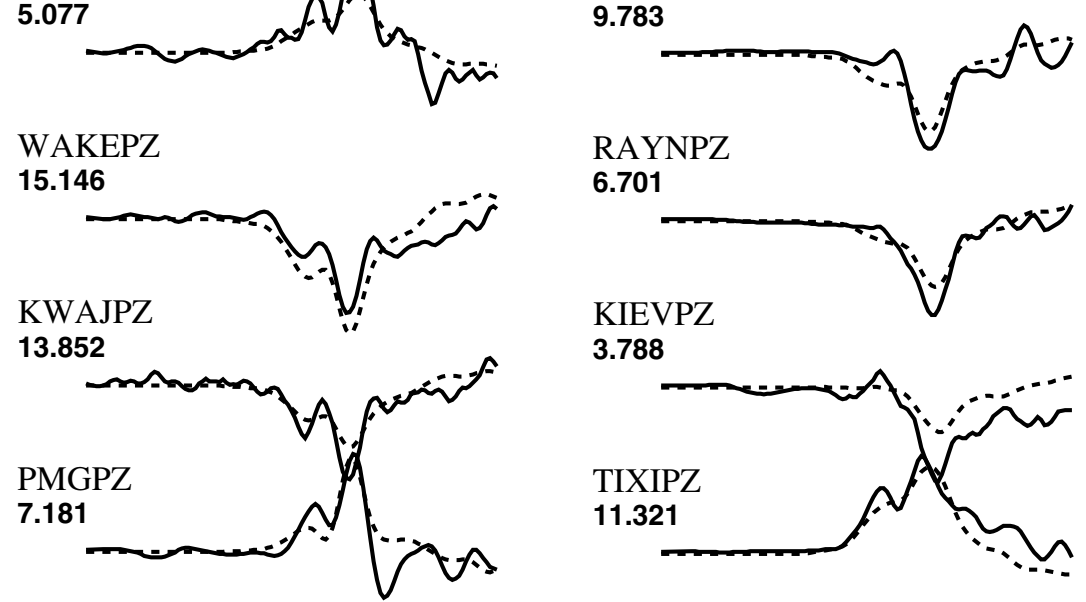

6.701
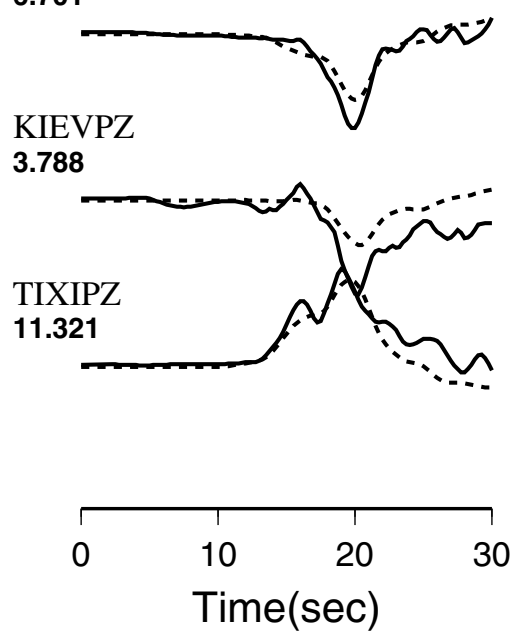

Figure 7. Strong-motion velocity waveforms recorded at near-source stations and $P$-wave displacement waveforms recorded at teleseismic stations, along with the corresponding synthetic waveforms obtained from kinematic inversion (Yagi, 2001). The waveforms are indicated by the station code and the component with the epicentral distance (in $\mathrm{km}$ for strong-motion stations and in degrees for teleseismic stations). 
(a) NWN

ESE

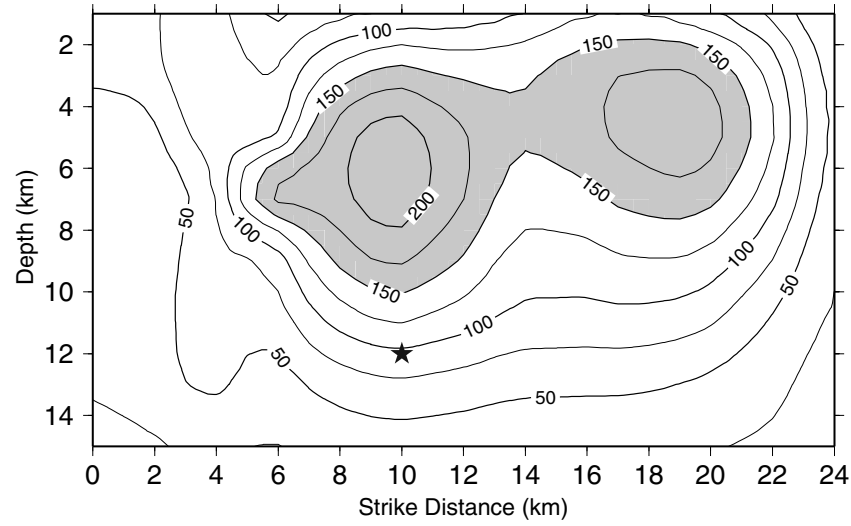

(b) NWN

ESE

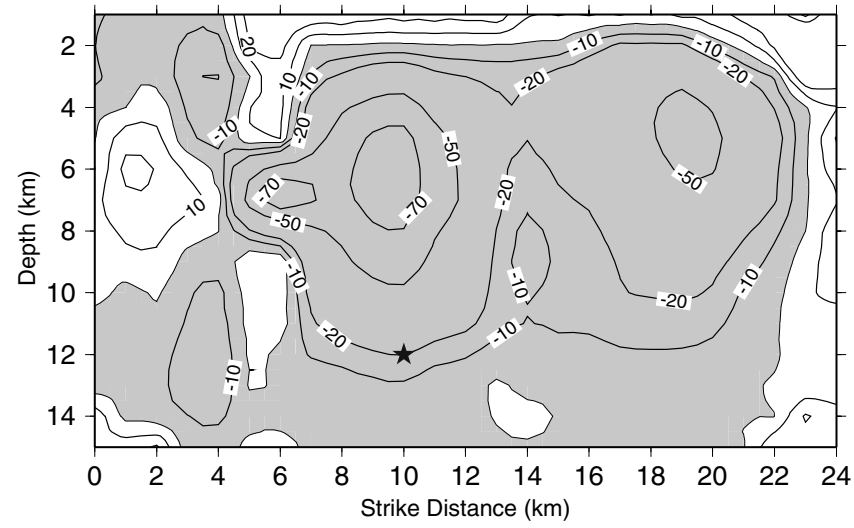

Figure 8. Spatial distribution of (a) slip (Yagi's final model) and (b) stress change for the Tottori earthquake. Shaded and white areas indicate zones of stress decrease and increase, respectively.

served waveform data, and $V_{\mathrm{av}}$ is the slip-velocity $(\mathrm{d} D / \mathrm{d} t)$ averaged over $T_{\text {cmin }}$. If we tentatively take the average as a half of its maximum value $V_{\max }$, then

$$
D_{\text {cmin }}=T_{\text {cmin }} V_{\max } / 2 .
$$

The observed records have been lowpass filtered applying a fourth-order butterworth filter with a high-cut frequency of $0.5 \mathrm{~Hz}$. This filter still retains amplitude levels of $70 \%$ at $0.5 \mathrm{~Hz}$ and $25 \%$ at $1 \mathrm{~Hz}$, suggesting that the shortest period remaining on the filtered records, $T_{\text {cmin }}$, will be about $1 \mathrm{sec}$. The maximum slip velocity obtained here ranges from 50 to $150 \mathrm{~cm} / \mathrm{sec}$ at different locations on the fault. If we use the above expression, the minimum resolvable $D_{\mathrm{c}}$ would be $25 \mathrm{~cm}$ to $75 \mathrm{~cm}$, depending on the location of the subfault, which seems to be quite large at points with large slip velocities.

The second step, for the case when its median value of $D_{\text {c }}$ exceeded the above minimum resolvable limit $D_{\text {cmin }}$, is to estimate the probable error of $D_{\mathrm{c}}$ from the breakdown time
$T_{\mathrm{c}}=T_{\mathrm{b}}-T_{\mathrm{r}}$. If we use the relation $D_{\mathrm{c}} \sim T_{\mathrm{c}} \Delta \sigma / \rho \beta$, which can be derived from Ohnaka and Yamashita (1989), then,

$$
\begin{aligned}
\Delta D_{\mathrm{c}} \sim \Delta T_{\mathrm{c}}(\Delta \sigma / \rho \beta), \text { and } & \Delta D_{\mathrm{c}} / D_{\mathrm{c}} \\
& =\Delta T_{\mathrm{c}} / T_{\mathrm{c}} \sim \Delta T_{\mathrm{c}}{ }^{\prime} / T_{\mathrm{c}}{ }^{\prime}
\end{aligned}
$$

where $\Delta \sigma$ and $\rho$ are the breakdown stress drop and density, respectively, and $T_{\mathrm{c}}{ }^{\prime}=T_{\mathrm{pv}}-T_{\mathrm{r}}$ is the time from the onset to the peak time. As described in the foregoing section for the kinematic waveform inversion, the source time function on each subfault is expanded into 39 sequential, overlapping triangular basis functions, each having a half duration of $0.25 \mathrm{sec}$ with a shift of $0.25 \mathrm{sec}$ and a resampling rate of $0.05 \mathrm{sec}$, to match the synthetics to the observed waveforms. This procedure yields the slip-velocity functions shown in Figure 9. In this procedure, we estimate a probable error $\Delta T_{\mathrm{c}}{ }^{\prime}$ to be less than $0.25+0.05=0.30 \mathrm{sec}$. Since $T_{\mathrm{c}}{ }^{\prime}$ in the slip-velocity functions is in the range between 1.2 and $2.6 \mathrm{sec}$, we find that $\Delta D_{\mathrm{c}} / D_{\mathrm{c}}$ ranges from $12 \%$ to $25 \%$ or $\Delta D_{\mathrm{c}}$ ranges from 6 to $22 \mathrm{~cm}$ depending on the location on the fault.

We also made another numerical experiments to check the effects of lowpass filtering of the simulated slip-velocity time functions on the estimate of $D_{\mathrm{c}}{ }^{\prime}$. This is made for the case with an initial stress of $22.5 \mathrm{MPa}$ plus a uniform random distribution between $+20 \mathrm{MPa}$ and $-20 \mathrm{MPa}$, being subjected to a yield stress of $25 \mathrm{MPa}$ and a prescribed value of $D_{\mathrm{c}}=20 \mathrm{~cm}$ over the entire fault. The initial stress was constrained to be less than $95 \%$ of the yield stress to prevent rupture initiation from several locations on the fault. Other fault parameters are similar to case 1 in Table 1 . This calculation allows a maximum frequency of $3 \mathrm{~Hz}$ to be resolved assuming six points per minimum wavelength. The results shown in Figure 12 indicate that the $D_{\mathrm{c}}{ }^{\prime}$ values estimated on the synthetics for cutoff frequencies of $0.5-3.0 \mathrm{~Hz}$ agree with each other within less than 5\%. Thus, the above effects are found to be quite small as compared with the other uncertainties.

To estimate the upper bound of $D_{\mathrm{c}}$, we also constructed the stress-slip relations directly from the slip-velocity functions given in Figure 9, which are consistent with the spatial distribution of the final slip and static stress changes shown in Figure 8. To do this, the stress time functions were calculated by convolving the kernel involved in equation (7) in Fukuyama and Madariaga (1998) with the given slip-velocity functions. Figure 13 depicts the calculated stress and slip time histories on all subfaults, where the slip-velocity functions are the same as shown in Figure 9. Figure 14a shows the time histories on subfault $b$, and Figure 14b gives the stress-slip relation obtained in this case. This relation may be regarded as an apparent slip-weakening behavior, from which we see that the slip-weakening distance could be as long as $1.6 \mathrm{~m}$. It is possible, however, that the stress time function might be somewhat elongated due to the finite grid size and time increment used here. This artificial effect has 


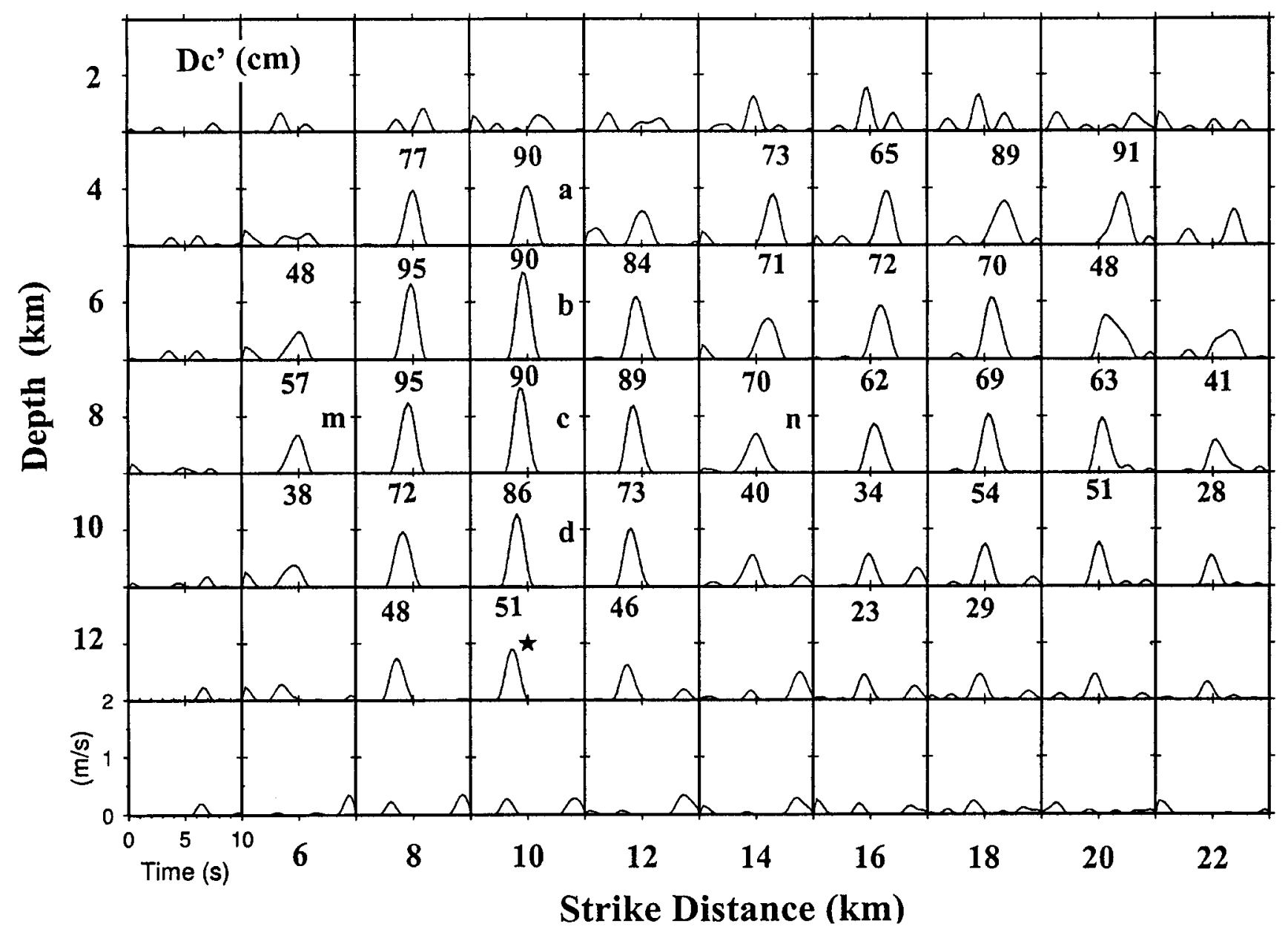

Figure 9. Slip-velocity functions on the subfaults of the segment FD2 for Yagi's final model of the Tottori earthquake. The numerals at the top on each subfault indicate $D_{\mathrm{c}}{ }^{\prime}$ (in $\mathrm{cm}$ ) integrated from the slip-velocity functions. Letters $\mathrm{a}, \mathrm{b}, \mathrm{c}, \mathrm{d}, \mathrm{m}$, and $\mathrm{n}$ denote the indices of the subfaults.

been shown by Ide and Takeo (1997) from their resolution analysis, which performed a similar inversion of synthetic seismograms generated from instantaneous stress drop $\left(D_{\mathrm{c}}\right.$ $=0$ ), with the same basis function and bandpass filtering as in the actual analysis. Their results suggest that the actual slip-weakening distance would be obtained only if this possible artificial effect was corrected. Thus, the slip-weakening distance seen from Figure 14b could be regarded as the upper bound of its actual value, which provides another constraint on $D_{\text {c. }}$.

\section{Spatial Distribution of $D_{\mathrm{c}}$}

The $D_{\mathrm{c}}$ values estimated above are plotted with the minimum resolvable limit and probable errors versus the local maximum slip in Figure 15. In most cases, $D_{\mathrm{c}}$ with large error bars for $\Delta D_{\mathrm{c}}$ appears to be somewhat above the minimum resolvable limit $D_{\text {cmin }}$. If this is the case, it appears that the median value of $D_{\mathrm{c}}$ increases with the local maximum slip on each subfault, which tends to fall in the range 0.27 $<D_{\mathrm{c}} / D_{\max }<0.56$. However, if the estimates of $T_{\mathrm{cmin}}$ and the average slip-velocity are somewhat larger than assumed here, the above trend would become quite marginal.

Taking these uncertainties both in kinematic and dynamic calculations into consideration, we tentatively divide the estimated slip-weakening distance $D_{\mathrm{c}}$ into four ranges. Figure 16 shows the distribution of the estimated ranges of $D_{\mathrm{c}}$ values on the main part of the fault. For some of the peripheral subfaults, the estimated values may be less reliable due to small peak slip velocities or shapes of the slipvelocity functions contaminated by spurious oscillations. Also in some subfaults closer to the east-southeast fault edge, our technique does not apply because of negative stress drop (stress increase), and these subfaults are therefore excluded in Figure 16 . From Figure 16, we see that $D_{\mathrm{c}}$ values larger than $80 \mathrm{~cm}$ are distributed on the subfaults in the strike direction between 8 and $12 \mathrm{~km}$ at depths between 4 and 10 $\mathrm{km}$ and at distances between 18 and $20 \mathrm{~km}$ at a depth around $4 \mathrm{~km}$. The zones of smaller $D_{\mathrm{c}}$ values between 40 and 60 $\mathrm{cm}$ are located not only near the hypocenter but also around the zones with larger values of $D_{\mathrm{c}}$. This pattern does not 



Figure 10. Time histories of stress, slip, and slip velocity at two selected points $\mathrm{B}(\mathrm{b})$ and $\mathrm{M}(\mathrm{m})$, calculated from the dynamic rupture for prescribed values of $D_{\mathrm{c}}=30$ $\mathrm{cm}$ and $D_{\mathrm{c}}=70 \mathrm{~cm}$.
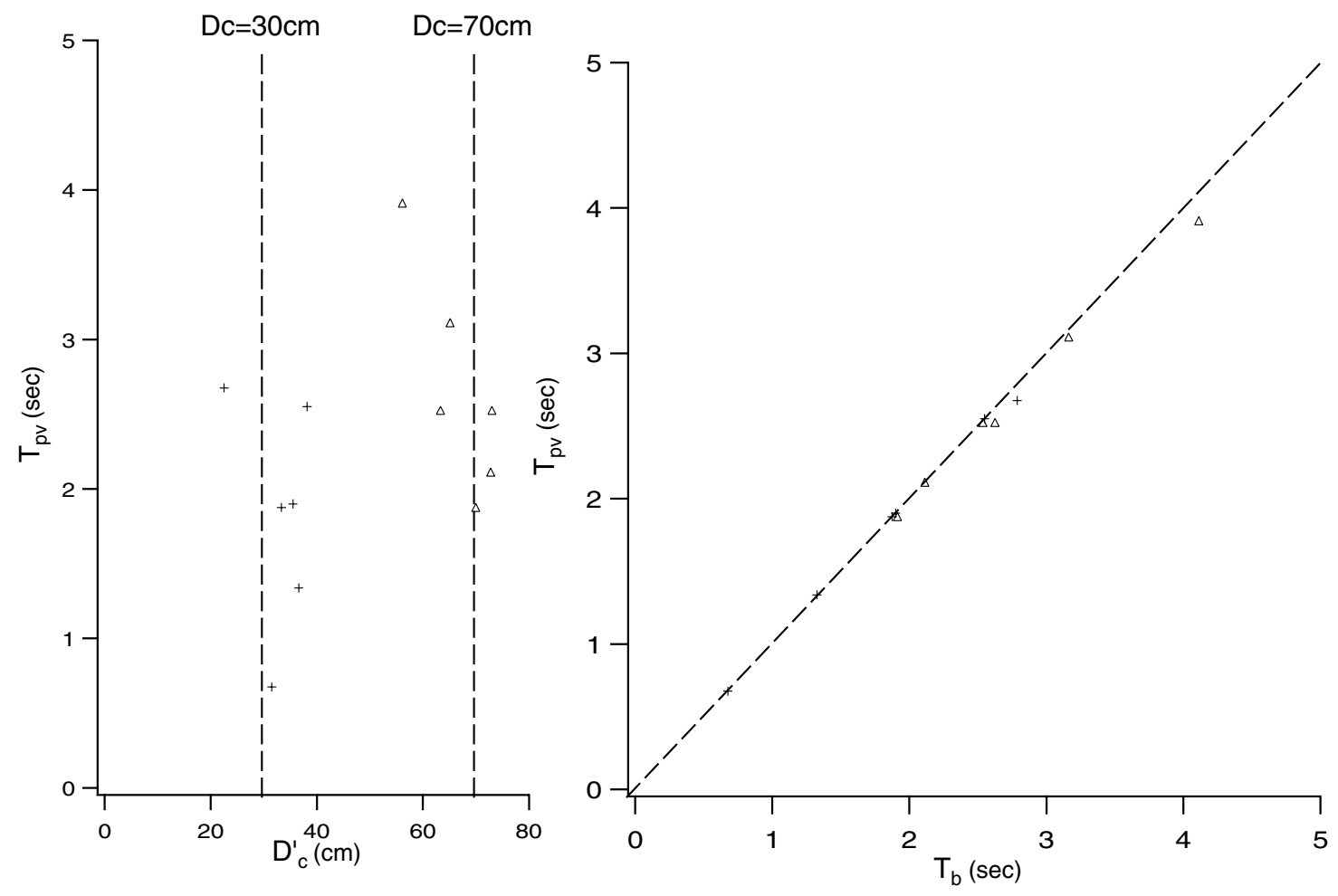

Figure 11. Relation between $T_{\mathrm{pv}}$ and $T_{\mathrm{b}}$ (right) and $D_{\mathrm{c}}{ }^{\prime}$ at $T_{\mathrm{pv}}$ (left) for the case shown in Figure 10. $T_{\mathrm{b}}$ and $T_{\mathrm{pv}}$ are measured from the origin time at the rupture starting point. 




Figure 12. Effect of low-pass filtering of the simulated slip-velocity and slip functions on the estimate of $\mathrm{D}_{\mathrm{c}}{ }^{\prime}$ for a prescribed value of $D_{\mathrm{c}}=20 \mathrm{~cm}$. The five different curves correspond to the cases of using cutoff frequencies of $0.5,1,2$, and $3 \mathrm{~Hz}$.
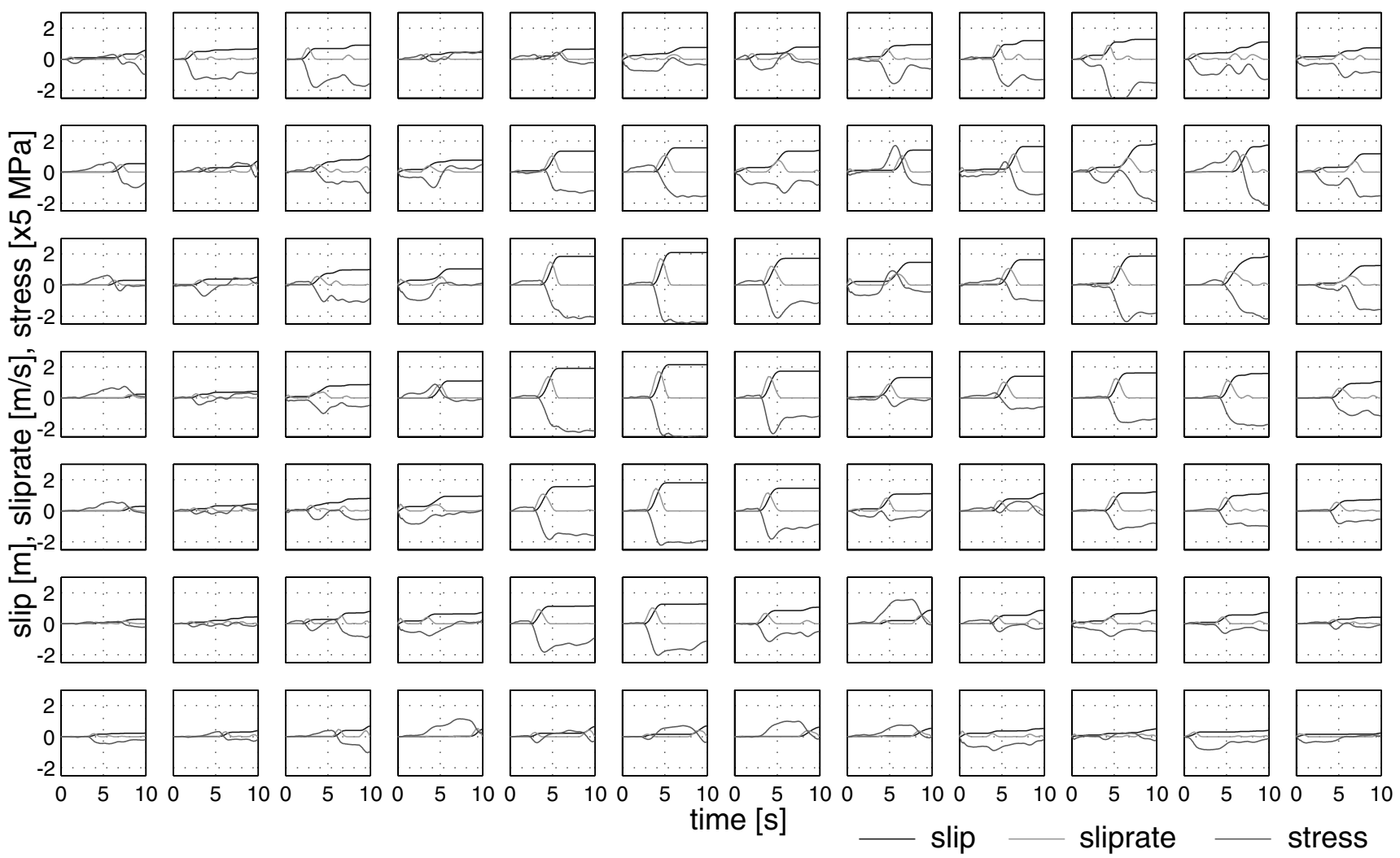

Figure 13. Time histories of stress, slip, and slip velocity on all subfaults, calculated from Yagi's (2001) slip-velocity time functions shown in Figure 9. 
a)

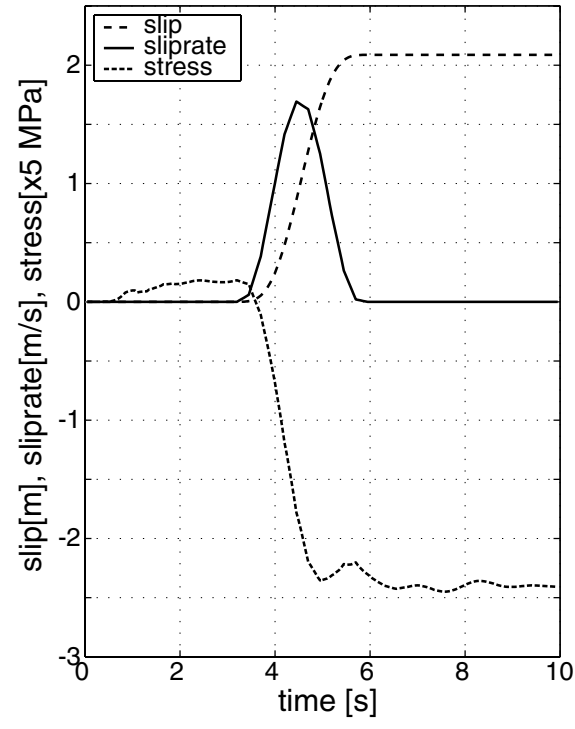

b)

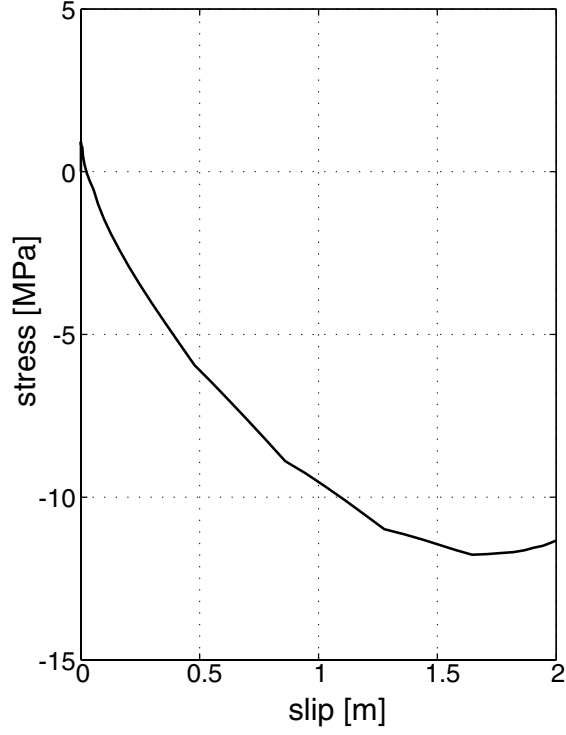

Figure 14. (a) Same as Figure 13 at point b, (b) apparent slip-weakening relation in (a).

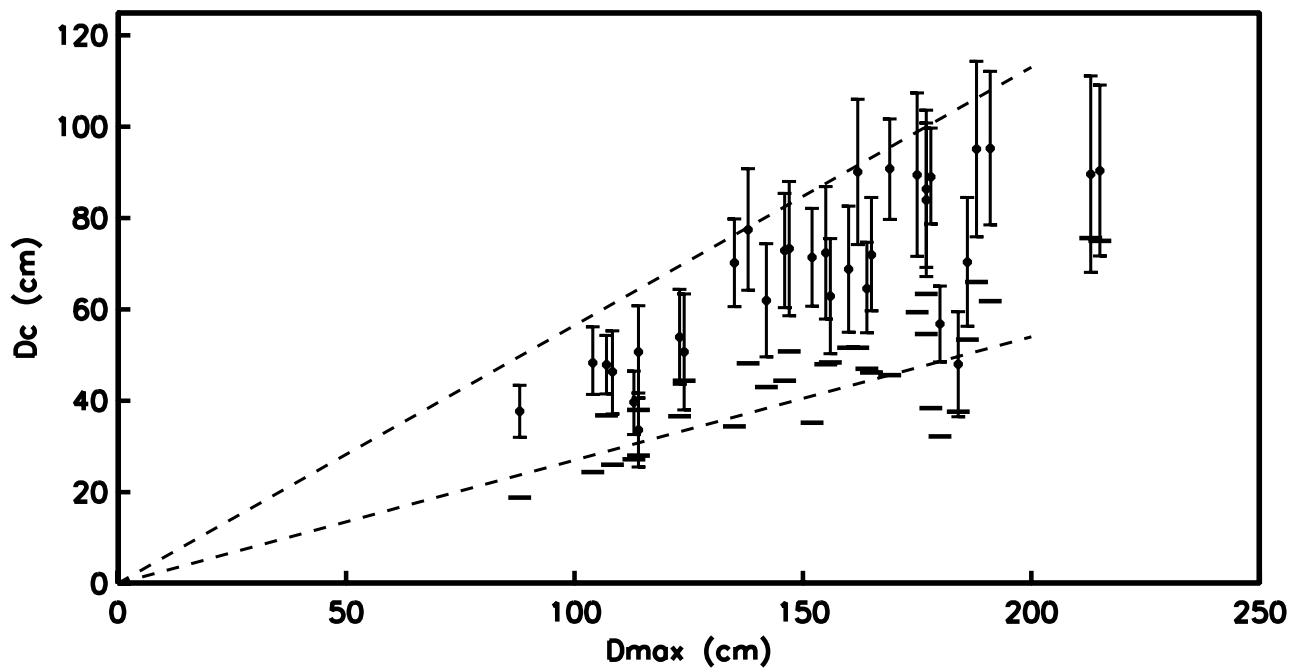

Figure 15. The estimated $D_{\mathrm{c}}$ values with their minimum resolvable limit (thick horizontal bars) and probable errors (thin vertical lines) plotted versus the local maximum slip on all subfaults. The two dashed lines depict the upper and lower ranges of data $D_{\mathrm{c}}=0.56 D_{\max }$ (upper) and $D_{\mathrm{c}}=0.27 \mathrm{D}_{\max }$ (lower).

necessarily indicate larger $D_{\mathrm{c}}$ at shallow fault sections nor smaller $D_{\mathrm{c}}$ at deeper fault sections, but rather a spatially heterogeneous distribution.

\section{The 1995 Kobe Earthquake}

Now, we compare the results for the 2000 Tottori earthquake with those for the 1995 Kobe earthquake $\left(M_{\mathrm{w}} 7.2\right)$. The mainshock of the Kobe earthquake was located at $34.61^{\circ}$ $\mathrm{N}$ and $135.04^{\circ} \mathrm{E}$ at a depth of $14.3 \mathrm{~km}$ (JMA). All the CMT solutions obtained by different institutions indicate a strikeslip mechanism with nearly vertical nodal planes, one of which is parallel and consistent with the direction of linea- tion of the aftershock distribution. The earthquake was recorded at 18 JMA stations located within $150 \mathrm{~km}$ from the epicenter. Ide and Takeo (1997) performed kinematic waveform inversion of 45 displacement seismograms integrated from the recorded accelerograms, which have been bandpass-filtered from 0.025 to $0.5 \mathrm{~Hz}$, to obtain a slip distribution over the fault. The inversion was made for the nearly vertical fault with a dimension of $50 \mathrm{~km} \times 20 \mathrm{~km}$, which was divided into $20 \times 8$ subfaults with a size of $2.5 \mathrm{~km} \times$ $2.5 \mathrm{~km}$. The source time function used by Ide and Takeo (1997) is the superposition of six triangles, each with a half duration of $0.6 \mathrm{sec}$ at a time interval of $0.2 \mathrm{sec}$. 


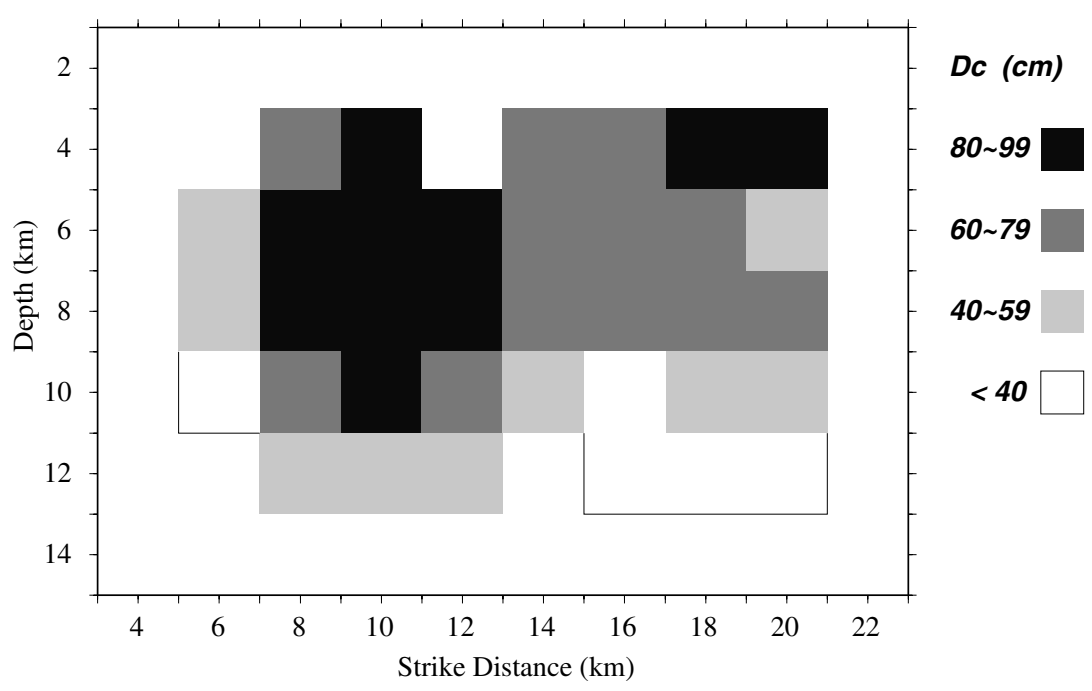

Figure 16. Spatial distribution of the estimated $D_{\mathrm{c}}$ values on the main part of the Tottori earthquake fault, which are tentatively classified into four ranges.
Figure 17 reproduces the spatial distribution of slip and the slip-velocity functions at 10 selected points $(a-j)$ in the shallow fault section, at depths near the hypocenter, and in the deeper part (Ide and Takeo, 1997). We apply our method to these slip-velocity functions to obtain approximate estimates of $D_{\mathrm{c}}$. For this purpose, we integrate the slip-velocity functions from the arrival time of rupture (all reduced to the origin time) to the time of peak slip-velocity, providing $D_{\mathrm{c}}{ }^{\prime}$ at time $T_{\mathrm{pv}}$. The calculated values of $D_{\mathrm{c}}{ }^{\prime}$ are listed at the left top of each point. Three points- $\mathrm{d}$, g, and $\mathrm{j}$-have been excluded because of somewhat noisy shapes of their slipvelocity functions. We find that $D_{\mathrm{c}}{ }^{\prime}$ at four points-e, f, h, and $\mathrm{i}-\mathrm{in}$ the deeper fault section are in the range between 40 and $50 \mathrm{~cm}$ and that point b in the shallow part yields $D_{\mathrm{c}}{ }^{\prime}$ $=90 \mathrm{~cm}$ whereas $D_{\mathrm{c}}{ }^{\prime}$ at two points a and c ranges between 50 and $60 \mathrm{~cm}$. We did not correct $D_{\mathrm{c}} / D_{\mathrm{c}}{ }^{\prime}$ for these values from dynamic rupture calculations. From equations (4) and (5) and the observed peak slip-velocities, however, we expect that the minimum resolvable $D_{\mathrm{c}}{ }^{\prime}$ will be about $25 \mathrm{~cm}$ and that the probable error of the $D_{\mathrm{c}}^{\prime}{ }^{\prime}$ values will be in the range between $25 \%$ and $40 \%$ considering the duration and time interval of the source time function used in their waveform inversion. On the other hand, the $D_{\mathrm{c}}$ values estimated by Ide and Takeo (1997) from the stress-slip relation should be regarded as the upper bound of their real values because of resolution problems due to the limited grid size and time increment (Ide and Takeo, 1997). The above values estimated here are almost all consistent with those for the Tottori earthquake fault. While smaller values can be found in the deeper fault section as have been stated by Ide and Takeo (1997), all seven values appear spatially variable rather than depth dependent, and a fraction of the local maximum slip. This pattern is also consistent with the case of the Tottori earthquake.

\section{Discussion}

Our numerical calculations and discussions are entirely based on the simple slip-weakening model given by An- drews (1976a, b), in which the shear stress decreases linearly with ongoing slip up to the critical weakening slip $D_{\mathrm{c}}$. However, actual slip-weakening behavior could be different from this idealized case. Actually, Ida (1972), Ohnaka and Yamashita (1989), Matu'ura et al. (1992), and Campillo et al. (2001) presented somewhat different slip-weakening laws based either on theoretical considerations or on laboratory experiments. Fukuyama et al. (2002) used numerical calculations of dynamic rupture, assuming five different types of slip-weakening friction with the same fracture energy $G$, to investigate the effect of possible differences in the stress change behavior on the relations $T_{\mathrm{b}} \sim T_{\mathrm{pv}}$ and $D_{\mathrm{c}}{ }^{\prime} \sim D_{\mathrm{c}}$. The results show that for the cases of sharp stress drop around $T_{\mathrm{b}}$, the deviations of $D_{\mathrm{c}}{ }^{\prime}$ from the prescribed value of $D_{\mathrm{c}},\left(D_{\mathrm{c}}{ }^{\prime}-D_{\mathrm{c}}\right) / D_{\mathrm{c}}$, are mostly within $20 \%$ at a number of points on the fault, but that the cases with very gentle decrease of stress yield quite large deviations sometimes even up to $50 \%$. For more details, see Fukuyama et al. (2002). The large deviations in some cases impose another limitation in applying the present technique to estimate the slip-weakening distance $D_{\mathrm{c}}$ from the observed time of peak slip-velocity $T_{\mathrm{pv}}$ on the fault.

All the uncertainties described previously, including the limited frequency resolution of the observed waveforms and probable time errors in the slip-velocity functions obtained from kinematic inversion, deviations of $T_{\mathrm{pv}}$ from $T_{\mathrm{b}}$ in dynamic rupture, and the possibility of different types of slipweakening behaviors, which could reach a factor of about 2 if all combined, preclude exact estimates of the slip-weakening distance. Accordingly, the $D_{\mathrm{c}}$ values estimated here are limited by the bandwidth of frequency between 0.05 and $0.5 \mathrm{~Hz}$ and are hence constrained to be between the lowest resolvable limit and the upper bound of their real values. This means that any $D_{\mathrm{c}}$ values less than the minimum resolvable limit, if present, have not been resolved in this study. Moreover, for very sharp initiation of the slip-velocity functions similar to that for a Kostrov-type crack model with $D_{\mathrm{c}} \sim 0$ assumed in the 1984 Morgan Hill, California, earth- 


\section{$\mathbf{D c} \sim(\mathbf{c m})$}

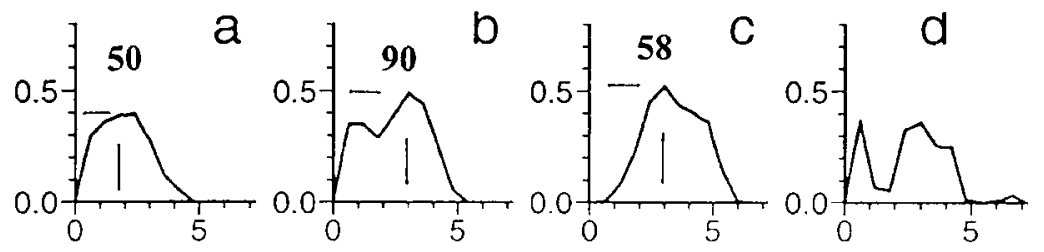

\section{Slip Rate}

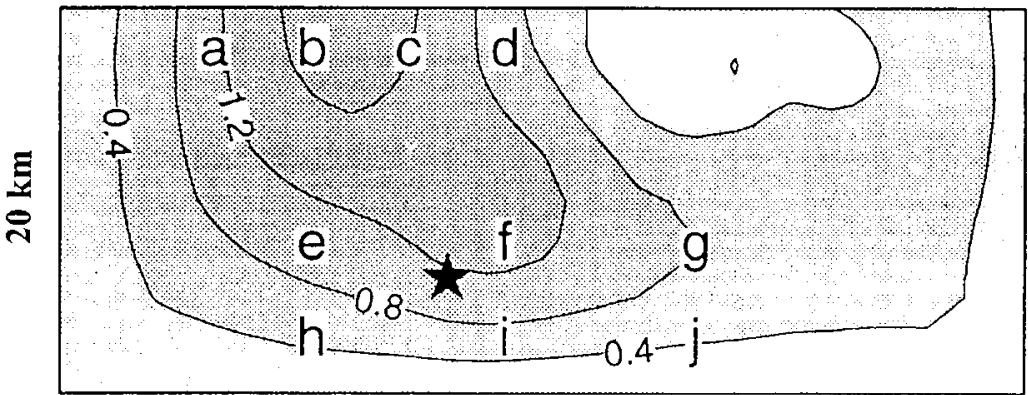

\section{Slip \\ Distribution}

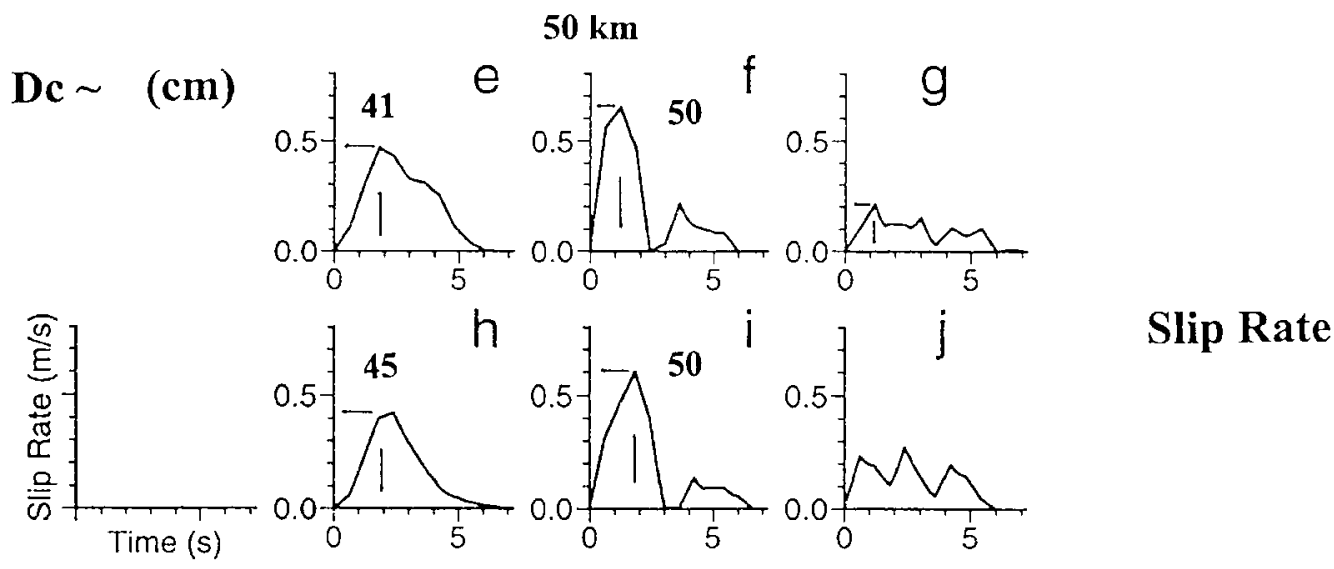

Figure 17. Slip distribution and slip-velocity functions at selected points on the fault for the 1995 Kobe earthquake (Ide and Takeo, 1997). The numerals at the upper left corner indicate $D_{\mathrm{c}}{ }^{\prime}$ estimated from the slip-velocity functions. Modified, with permission from American Geophysical Union, from figure 4 on p. 27,384 of Ide and Takeo (1997). (Copyright 1997 by the American Geophysical Union.)

quake (Beroza and Spudich, 1988; Beroza and Mikumo, 1996), $D_{\text {c }}$ cannot be resolved by the present technique. This also suggests that our method may not be applicable for much smaller earthquakes with possibly very small $D_{\mathrm{c}}$ values, unless much higher frequency band is used for the analysis.

Now, we discuss other dynamic parameters that might be roughly estimated from our calculations. For the Tottori earthquake fault, the actual breakdown time of stress $T_{\mathrm{c}}$ is estimated from 1.2 to $2.6 \mathrm{sec}$ except at a few points. For the Kobe earthquake, on the other hand, $T_{\mathrm{c}}$ (not corrected) ranges between 1.3 and $3.0 \mathrm{sec}$, which is slightly longer than for the case of the Tottori earthquake. This minor difference may not be important in view of the limitations of the present technique. The strength excess $\sigma_{\mathrm{y}}-\sigma_{0}$ may be estimated from dynamic rupture calculations when the rupture arrival time at each point on the fault is specified (Miyatake, 1992; Mikumo and Miyatake, 1995). Although $T_{\mathrm{r}}$ has been estimated within an error of $0.25 \mathrm{sec}$ from the kinematic inversion, the rupture arrival times expected from a fixed velocity of $0.7 \beta$ for each layer are imposed, instead, in this specific case. For the Tottori earthquake, the strength excess is found to be between 1.5 and $5.0 \mathrm{MPa}$, although these values may not be well resolved because of the grid spacing used in the numerical calculations. The breakdown stress drop $\sigma_{\mathrm{y}}-\sigma_{\mathrm{f}}$ $=\left(\sigma_{\mathrm{y}}-\sigma_{0}\right)+\left(\sigma_{0}-\sigma_{\mathrm{f}}\right)$ in the zone of maximum dynamic stress drop is about $11 \mathrm{MPa}$. By combining the already estimated slip-weakening distance $D_{\mathrm{c}}$ with the breakdown stress drop, the fracture energy $G=\left(\sigma_{\mathrm{y}}-\sigma_{\mathrm{f}}\right) D_{\mathrm{c}} / 2$ for this zone is found to be on the order of $5 \mathrm{MJ} / \mathrm{m}^{2}$. This is the same order of magnitude as found in the Morgan Hill (Beroza and Spudich, 1988) and the 1992 Landers (Olsen et al., 1997), 
California, earthquakes. All these estimates are obtained from Yagi's (2001) kinematic slip model. It is possible that these values and the spatial distribution of $D_{\mathrm{c}}$ could be slightly different if we refer to other slip models (e.g., Fukuyama and Dreger, 2001; Iwata and Sekiguchi, 2001).

From the results of waveform inversion, Ide and Takeo (1997) found that the slip-weakening distance $D_{\mathrm{c}}$ for the shallow part of the fault is larger than that for the deeper fault sections in the Kobe earthquake. Scholz (1988) has suggested that long-wavelength aperture involved in nearsurface rock materials start to close with increasing depth, which makes the slip-weakening distance smaller, while Marone and Kilgore (1993) claimed that thicker fault gouge may cause larger values of $D_{\mathrm{c}}$ in the shallow crust. As shown in Figures 16 and 17, however, the slip-weakening distance for both the Tottori and Kobe earthquakes appears to be slightly dependent on depth but rather spatially variable and more dependent on the local maximum slip, although our estimates have quite large uncertainty as mentioned before. Similar variation has been noticed in the results by Pulido and Irikura (2000) for the 1992 Landers earthquake, although the ratio of $D_{\mathrm{c}}$ to the average slip in their case reaches $70 \%$ to $90 \%$, which appears quite large from our point of view. If we take these cases into account, it would follow that physical properties controlling both the slip-weakening distance and the final fault slip could be either the characteristic wavelength of fault roughness (Ohnaka and Shen, 1999 ) or the thickness of fault gouge layer (Marone and Kilgore, 1993), in addition to the stress distribution on the fault.

The possibility of scale effects of the slip-weakening distance with earthquake size has not been resolved in the present study because we have dealt only with two strikeslip earthquakes with a similar magnitude and a similar mechanism. However, from the apparent slip dependence of the slip-weakening distance shown in Figure 15, if it actually exceeds the lowest resolvable limit, it could be speculated that $D_{\mathrm{c}}$ on faults of smaller-size earthquakes, such as aftershocks on part of the same fault, might be smaller because of smaller final slip. If this is the case, the values of $D_{\mathrm{c}}$ appear to be distributed indicating a fractal-like structure of the roughness of the fault surface. It has been shown by laboratory experiments (Okubo and Dieterich, 1984; Ohnaka and Shen, 1999) that the slip-weakening distance increases with increased fault roughness. Surveys of natural faults (Scholz and Aviles, 1986; Power et al., 1987) also suggested that the topography or roughness of fault surfaces is nearly fractal and hence that the slip-weakening distance controlled by the fault roughness is expected to scale with slip. If so, smaller earthquakes with smaller $D_{\mathrm{c}}$ could also nucleate on the same fault for the same order of dynamic stress drop, as is clear from equation (3) (Day, 1982). This observation also suggests that $D_{\mathrm{c}} / D_{\max }$ may be roughly the seismic efficiency (i.e., the ratio of the seismic wave radiation energy to the total energy including the fracture energy) (H. Kanamori, personal comm., 2002). To address these problems, future efforts should apply the present approach to smallermagnitude earthquakes in the continental crust and also to extremely large thrust earthquakes in subduction zones, taking into account the broadband frequency range of seismic observations.

Finally, the approach described here could also be applied to near-fault strong-motion records, assuming that the strike-parallel slip-velocity and displacement waveforms are approximate expressions of the source time functions on the fault (Olsen et al., 2002).

\section{Conclusions}

We present a new approach to estimate the slip-weakening distance on earthquake faults from the slip-velocity functions obtained from inversion of strong-motion records, independently from the estimate of the fracture energy or radiated seismic energy. The approach provides a physically based relation between the breakdown time of shear stress $T_{\mathrm{b}}$, the time of peak slip-velocity $T_{\mathrm{pv}}$, and the slip-weakening slip $D_{\mathrm{c}}$, through dynamic rupture calculations using a simple slip-weakening friction law. Numerical calculations show that $T_{\mathrm{pv}}$ is well correlated with $T_{\mathrm{b}}$ for faults even with heterogeneous stress-drop distributions, except at points in front of strong barriers and near the edges of the fault.

The aforementioned method has been applied to two recent, strike-slip earthquakes in western Japan: the 2000 Tottori and the 1995 Kobe earthquakes. By integrating the slip-velocity functions on the vertical fault, which had been obtained from kinematic waveform inversion of strongmotion and teleseismic records, we obtain the slip at time $T_{\mathrm{pv}}$ and then correct it for the errors expected from dynamic calculations. We also estimated the lowest resolvable limit, the upper bound, and probable errors of $D_{\mathrm{c}}$ from the slipvelocity functions. We found that the actual stress-breakdown time ranges from 1.2 to $3.0 \mathrm{sec}$, and the slip-weakening distance $D_{\mathrm{c}}$ estimated in the frequency band between 0.05 and $0.5 \mathrm{~Hz}$ ranges between 40 and $90 \mathrm{~cm}$ on the two earthquake faults. The fracture energy in the zone of maximum slip for the Tottori earthquake is found to be on the order of $5 \mathrm{MJ} / \mathrm{m}^{2}$. However, from all uncertainties involved in the kinematic and dynamic calculations, the above estimates are limited to the range between the minimum resolvable limit and the upper bound of their real values. The estimated $D_{\mathrm{c}}$ values do not seem to be necessarily depth dependent but rather spatially heterogeneous and appear to be dependent on the local maximum slip. This possible dependence may be interpreted by the frictional properties of the fault such as the degree of roughness and/or the thickness of gouge layers, in addition to the stress heterogeneities.

\section{Acknowledgments}

The senior author greatly benefited from conversations with James $\mathrm{R}$. Rice at an early stage of the present study and wishes to thank Miti Ohnaka, Raul Madariaga, and Hiroo Kanamori for some discussion about the present 
topics and their constructive comments. We also thank Paul Spudich, Steve Day, and Michel Bouchon (Associate Editor) for their critical and helpful reviews, which greatly improved our original manuscript. Thanks are extended to Satoshi Ide for permitting us to reproduce one of the diagrams from the Kobe earthquake and also to Shri Krishna Singh and Javier Pacheco for their comments. Miguel A. Santoyo and Arturo Iglesias kindly prepared a few figures and files included in the text. Tomotaka Iwata and Takuro Shibutani provided their preliminary reports on the Tottori earthquake. The present work is based on strong-motion data obtained at the stations operated by National Research Institute for Earth Sciences and Disaster Prevention and Japan Meteorological Agency. This study is partly supported by the CONACyT (Mexico) Project No. 32541-T, for which we thank the assistance by Raul Valenzuela. A part of the calculations were made through supercomputers at the Computer Center of the Universidad Nacional Autonoma de Mexico. The work by Kim B. Olsen was supported by the National Science Foundation, award number EAR-0003275 and the Southern California Earthquake Center (SCEC). The SCEC is funded by National Science Foundation Cooperative Agreement EAR-8920136 and U.S. Geological Survey Cooperative Agreements 14-08-0001-A0899 and 1434-HQ-97AG01718. The SCEC Contribution Number for this article is 696 and the ICS Contribution Number is 498.

\section{References}

Aki, K., and A. Papageorgiou (1988). Separation of source and site effects in acceleration power spectra of major California earthquakes, Proc. 9th World Conf. Earthq. Eng. VIII, 163-165.

Andrews, D. J. (1976a). Rupture propagation with finite stress in antiplane, J. Geophys. Res. 81, 3575-3582.

Andrews, D. J. (1976b). Rupture velocity of plane strain shear cracks, $J$. Geophys. Res. 81, 5679-5687.

Beroza, G. C., and T. Mikumo (1996). Short slip duration in dynamic rupture in the presence of heterogeneous fault properties, J. Geophys. Res. 101, 22,449-22,460.

Beroza, G. C., and P. Spudich (1988). Linearized inversion for fault rupture behavior: application to the 1984 Morgan Hill, California, earthquake, J. Geophys. Res. 93, 6275-6296.

Campillo, M., P. Favreau, I. R. Ionescu, and C. Voisin (2001). On the effective friction law of a heterogeneous fault, J. Geophys. Res. 106, $16,307-16,322$.

Clayton, R., and B. Engquist (1977). Absorbing boundary conditions for acoustic and elastic equations, Bull. Seism. Soc. Am. 67, 1529-1540.

Day, S. M. (1982). Three-dimensional simulation of spontaneous rupture: the effect of nonuniform prestress, Bull. Seism. Soc. Am. 72, 18811902.

Day, S. M., G. Yu, and D. J. Wald (1998). Dynamic stress change during earthquake rupture, Bull. Seism. Soc. Am. 88, 512-522.

Dieterich, J. H. (1979). Modeling of rock friction 1: Experimental results and constitutive equations, J. Geophys. Res. 84, 2161-2168.

Dieterich, J. H. (1981). Constitutive properties of faults with simulated gouge, Geophys. Monograph Am. Geophys. Union 24, 103-120.

Dieterich, J. H., and B. Kilgore (1996). Implication of fault constitutive properties for earthquake prediction, Proc. Natl. Acad. Sci. USA 93, 3787-3794.

Ellsworth, W. L., and G. C. Beroza (1995). Seismic evidence for an earthquake nucleation phase, Science 268, 851-855.

Fukuyama, E., and R. Madariaga (1995). Integral equation method for plane crack with arbitrary shape in 3D elastic medium, Bull. Seism. Soc. Am. 85, 614-628.

Fukuyama, E., and R. Madariaga (1998). Rupture dynamics of a planar fault in a 3D elastic medium: rate- and slip-weakening friction, Bull. Seism. Soc. Am. 88, 1-17.

Fukuyama, E., and R. Madariaga (2000). Dynamic propagation and interaction of a rupture front on a planar fault, Pure Appl. Geophys. 157, 1959-1979.

Fukuyama, E., M. Ishida, S. Horiuchi, H. Inoue, S. Hori, S. Sekiguchi,
T. Eguchi, A. Kubo, H. Kawai, M. Murakami, S. Yamamoto, and K. Nonomura (2001), NIED seismic moment tensor catalogue JanuaryDecember, 2000, Technical Note to the National Institute for Earth Sciences and Disaster Prevention 217, 1-131.

Fukuyama, E., T. Mikumo, and K. B. Olsen (2003). Estimation of critical slip-weakening distance: its theoretical background, Bull. Seism. Soc. Am. (submitted for publication).

Guatteri, M., and P. Spudich (2000). What can strong-motion data tell us about slip-weakening fault-friction laws? Bull. Seism. Soc. Am. 90, 98-116.

Ida, Y. (1972). Cohesive force across the tip of a longitudinal shear crack and Griffith's specific surface energy, J. Geophys. Res. 84, 37963805.

Ide, S., and M. Takeo (1997). Determination of constitutive relations of fault slip based on seismic wave analysis, J. Geophys. Res. 102, 27,379-27,391.

Iwata, T., and H. Sekiguchi (2001). Inferences of earthquake rupture process from strong-motion records, presented at the Symposium for Strong-Motion Network.

Kato, N., and T. E. Tullis (2001). A composite rate- and state-dependent law for rock friction, Geophys. Res. Lett. 28, 1103-1106.

Kikuchi, M., and H. Kanamori (1991). Inversion of complex body waves III, Bull. Seism. Soc. Am. 81, 2335-2350.

Kinoshita, S. (1998). Kyoshin Net (K-NET), Seism. Res. Lett. 69, 309-332.

Koketsu, K. (1985). The reflectivity method for synthetic near-field seismograms, J. Phys. Earth 33, 121-131.

Levander, A. (1988). Fourth-order finite difference P-SV seismograms, Geophysics 53, 1425-1436.

Madariaga, R. (1976). Dynamics of an expanding circular fault, Bull. Seism. Soc. Am. 66, 639-667.

Madariaga, R., and K. B. Olsen (2000). Criticality of rupture dynamics in 3-D, Pure Appl. Geophys. 157, 1981-2001.

Madariaga, R., K. B. Olsen, and R. Archuleta (1998). Modeling dynamic rupture in a 3D earthquake fault model, Bull. Seism. Soc. Am. 88, 1182-1197.

Marone, C., and B. Kilgore (1993). Scaling of the critical slip distance for seismic faulting with shear strain in fault zones, Nature 362, 618621.

Matsu'ura, M., H. Kataoka, and B. Shibazaki (1992). Slip-dependent friction law and nucleation processes in earthquake rupture, Tectonophysics 211, 135-148.

Mikumo, T., and T. Miyatake (1995). Heterogeneous distribution of dynamic stress drop and relative fault strength recovered from the results of waveform inversion: 1984 Morgan Hill, California, earthquake, Bull. Seism. Soc. Am. 85, 178-193.

Mikumo, T., K. Hirahara, and T. Miyatake (1987). Dynamical fault rupture processes in heterogeneous media, Tectonophysics 144, 19-36.

Miyatake, T. (1980). Numerical simulation of earthquake source process by a three-dimensional crack model. I. Rupture process, J. Phys. Earth 28, 565-598.

Miyatake, T. (1992). Reconstruction of dynamic rupture process of an earthquake with constraints of kinematic parameters, Geophys. Res. Lett. 19, 349-352.

Ohnaka, M. (1996). Nonuniformity of the constitutive parameters for shear rupture and quasistaic nucleation to dynamic rupture: a physical model of earthquake generation processes, Proc. Natl. Acad. Sci. USA 93, 3795-3802.

Ohnaka, M. (2000). A physical scaling relation between the size of an earthquake and its nucleation zone size, Pure Appl. Geophys. 157, 2259-2282.

Ohnaka, M., and Y. Kuwahara (1990). Characteristic features of local breakdown near a crack-tip in the transition zone from nucleation to unstable rupture during stick-slip shear failure, Tectonophysics 175, 197-220.

Ohnaka, M., and L-f. Shen (1999). Scaling of the shear rupture process from nucleation to dynamic propagation: Implication of geometric irregularity of the rupturing surfaces, J. Geophys. Res. 104, 817-844. 
Ohnaka, M., and T. Yamashita (1989). A cohesive zone model for dynamic shear faulting based on experimentally inferred constitutive relation and strong-motion source parameters, J. Geophys. Res. 94, 40894104.

Ohnaka, M., Y. Kuwahara, and K. Yamamoto (1987). Constitutive relations between dynamic physical parameters near a tip of the propagating slip zone during stick-slip shear failure, Tectonophysics 144, 109125.

Okubo, P. G., and J. H. Dieterich (1984). Effects of physical fault properties on frictional instabilities produced on simulated faults, J. Geophys. Res. 89, 5817-5827.

Olsen, K. B. (1994). Simulation of three-dimensional wave propagation in the Salt Lake Basin, Ph.D. Thesis, University of Utah, $157 \mathrm{pp}$.

Olsen, K. B., and R. Archuleta (1996). Three-dimensional simulation of earthquakes on the Los Angeles Basin fault system, Bull. Seism. Soc. Am. 86, 575-596.

Olsen, K. B., R. Archuleta, and J. Matarese (1995). Three-dimensional simulation of a magnitude 7.75 earthquake on the San Andreas fault, Science 270, 1628-1632.

Olsen, K. B., E. Fukuyama, and T. Mikumo (2002). Direct measurement of slip-weakening friction from near-fault strong motion data, in Proc. 3rd ACES Workshop, Hawaii (in press).

Olsen, K. B., R. Madariaga, and R. J. Archuleta (1997). Three-dimensional dynamic simulation of the 1992 Landers earthquake, Science 278, 834-838.

Palmer, A. C., and J. R. Rice (1973). The growth of slip surfaces in the progressive failure of over-consolidated clay, Proc. R. Soc. London A 332, 527-548.

Papageorgiou, A. S., and K. Aki (1983). A specific barrier model for the quantitative description of inhomogeneous faulting and the prediction of strong-ground motion. II. Applications of the model, Bull. Seism. Soc. Am. 73, 953-978.

Peyrat, S., K. B. Olsen, and R. Madariaga (2001). Dynamic modeling of the 1992 Landers earthquake, J. Geophys. Res. 106, 26,467-26,482.

Power, W. L., T. E. Tullis, S. R. Brown, G. N. Boitnott, and C. H. Scholz (1987). Roughness of natural fault surfaces, Geophys. Res. Lett. 14, 29-32.

Pulido, N., and K. Irikura (2000). Estimation of dynamic rupture parameters from the radiated seismic energy and apparent stress, Geophys. Res. Lett. 27, 3945-3948.

Ruina, A. (1983). Slip instability and state variable friction laws, J. Geophys. Res. 88, 10,359-10,370.

Scholz, C. (1988). The critical slip distance for seismic faulting, Nature 336, 761-763.

Scholz, C., and C. A. Aviles (1986). The fractal geometry of faults and faulting, in Earthquake Source Mechanics, S. Das, J. Boatwright, and
C. H. Scholz, (Editors) American Geophysical Union Monograph 37 , Maurice Ewing Vol. 6, 147-155.

Shibazaki, B., and M. Matsu'ura (1992). Spontaneous processes for nucleation, dynamic propagation, and stop of earthquake rupture, Geophys. Res. Lett. 19, 1189-1192.

Shibazaki, B., and M. Matsu'ura (1998). Transition process from nucleation to high-speed rupture propagation: scaling from stick-slip experiments to natural earthquakes, Geophys. J. Int. 132, 14-30.

Shibutani, T., S. Nakao, R. Nishida, F. Takeuchi, K. Watanabe, and Y. Umeda (2002). Swarm-like seismic activities in 1989, 1990 and 1997 which preceded the 2000 Western Tottori earthquake, Earth Planets Space 54, 831-845.

Tullis, T. E. (1996). Rock friction and its implications for earthquake prediction examined via models of Parkfield earthquakes, Proc. Natl. Acad. Sci. USA 93, 3803-3810.

Virieux, J. (1986). P-SV wave propagation in heterogeneous media: velocity-stress finite difference method, Geophysics 51, 889-901.

Yagi, Y. (2001). Source rupture process of the Tottori-ken Seibu earthquake of Oct. 6, 2000, obtained by joint inversion of near-field and teleseismic data, presented at the Meeting of Japan Earth and Planetary Sciences, Tokyo, Japan, May 2001.

Instituto de Geofisica

Universidad Nacional Autonoma de Mexico

Mexico 04510 D.F., Mexico

mikumo@ollin.igeofcu.unam.mx

(T.M.)

Institute for Crustal Studies

University of California, Santa Barbara

Santa Barbara, California 93106-1100

kbolsen@crustal.ucsb.edu

(K.B.O)

National Research Institute for Earth Sciences and Disaster Prevention

Tsukuba, Ibaraki 305-0006, Japan

fuku@bosai.go.jp

(E.F.)

Earthquake Research Institute

University of Tokyo

Tokyo 113-0032, Japan

(Y.Y.)

Manuscript received 4 March 2002. 